\title{
1 Prediction and Validation of External Cooling Loop 2 Cryogenic Carbon Capture (CCC-ECL) for Full- 3 Scale Coal-Fired Power Plant Retrofit
}

5 Mark J. Jensen ${ }^{\dagger}$, Christopher S. Russell ${ }^{\dagger}$, David Bergeson ${ }^{\dagger}$, Christopher D. Hoeger ${ }^{\ddagger}$, David J.

6 Frankman , Christopher S. Bence ${ }^{+}$, and Larry L. Baxter ${ }^{*},+$,

8 'Department of Chemical Engineering, Brigham Young University, Provo, Utah 84602

$9 \quad{ }^{\ddagger}$ Sustainable Energy Solutions LLC, Orem, Utah 84058

10

11 KEYWORDS: Carbon Capture, $\mathrm{CO}_{2}$ Capture, $\mathrm{CO}_{2}$ Removal, Cryogenic Carbon Capture, $\mathrm{CCC}$, 12 CCC-ECL 
14 Bench-scale experiments and Aspen Plus ${ }^{\mathrm{TM}}$ simulations document full-scale, steady-state 15 performance of the external cooling loop cryogenic carbon capture (CCC-ECL) process for a 550

$16 \mathrm{MW}_{\mathrm{e}}$ coal-fired power plant. The baseline CCC-ECL process achieves $90 \% \mathrm{CO}_{2}$ capture, and 17 has the potential to capture $99+\%$ of $\mathrm{CO}_{2}, \mathrm{SO}_{2}, \mathrm{PM}, \mathrm{NO}_{2}, \mathrm{Hg}$, and most other noxious species. 18 The CCC-ECL process cools the power plant's flue gas to $175 \mathrm{~K}$, at which point solid $\mathrm{CO}_{2}$ 19 particles desublimate as the flue gas further cools to $154 \mathrm{~K}$. Desublimating flue gas cools in a 20 staged column in direct contact with a cryogenic liquid and produces a $\mathrm{CO}_{2}$-lean flue gas that 21 warms against the incoming flue gas before venting. The $\mathrm{CO}_{2} /$ contacting liquid slurry separates 22 through a filter to produce a $\mathrm{CO}_{2}$ stream that warms to $233 \mathrm{~K}$ and partially flashes to provide a $23 \mathrm{CO}_{2}$-rich product. The $\mathrm{CO}_{2}$-rich product (99.2 \%) liquefies under pressure to form a product for 24 enhanced oil recovery (EOR) or sequestration. All contacting liquid streams cool and cycle back 25 to the staged column. An internal $\mathrm{CF}_{4}$ refrigeration cycle transfers heat from melting $\mathrm{CO}_{2}$ to 26 desublimating $\mathrm{CO}_{2}$ by cooling contact liquid. An external cooling loop of natural gas or other 27 refrigerant provides the additional heat duty to operate the cryogenic process. The nominal 28 parasitic power loss of operating CCC-ECL is $82.6 \mathrm{MW}_{\mathrm{e}}$ or about $15 \%$ of the coal-fired power 29 plant's rated capacity. In different units, the energy penalty of CCC-ECL is $0.74 \mathrm{MJ}_{\mathrm{e}} / \mathrm{kg} \mathrm{CO}_{2}$ 30 captured and the resulting net power output is decreased to $467 \mathrm{MW}_{\mathrm{e}}$. Lab- and skid-scale 31 measurements validate the basic operation of the process along with the thermodynamics of $\mathrm{CO}_{2}$ 32 solids formation. 
34 Carbon dioxide $\left(\mathrm{CO}_{2}\right)$ affects the global climate in many ways. Within the USA, the

35 Environmental Protection Agency proposed regulations limit $\mathrm{CO}_{2}$ emissions from new electricity generation to $1,100 \mathrm{lbs}$. $\mathrm{CO}_{2} / \mathrm{MWh}(500 \mathrm{~kg} \mathrm{CO} / \mathrm{MWh})^{1}$. Even new supercritical coal-fired power plants require significant $\mathrm{CO}_{2}$ capture because their current $\mathrm{CO}_{2}$ emissions the range from 1,800 to 2,000 lbs. $\mathrm{CO}_{2} / \mathrm{MWh}\left(820-910 \mathrm{~kg} \mathrm{CO}_{2} / \mathrm{MWh}\right)^{2}$. Several technologies can achieve the necessary $\mathrm{CO}_{2}$ standard. However, while the regulations are obtainable with current technologies, the associated energy penalty of $\mathrm{CO}_{2}$ capture and resulting increased cost of electricity are substantial and pose significant changes to economies. A brief review of some competing technologies is presented as a reference. The main contribution of the present investigation is a description of external cooling loop cryogenic carbon capture (CCC-ECL), including skid-scale verification, and techno-economic simulations of a $90 \% \mathrm{CO}_{2}$ capture CCCECL process at full-scale on a coal-fired power plant with the associated energy and economic comparisons to a similar plant with no capture.

\section{Competing Technologies}

$\mathrm{CO}_{2}$ separation technologies target several industries, including energy production, cement production, aluminum and steel manufacturing, and natural gas production. Several reviews document the energy demands and costs for different technologies ${ }^{3-6}$. Technologies for coal-fired power plants generally fall into the categories of oxy-combustion, chemical looping, absorbents, adsorbents, membranes, and cryogenic processes. The minimum work to separate $90 \%$ of an initial $15 \%$ dry basis $\mathrm{CO}_{2}$ stream into one stream of pure $\mathrm{CO}_{2}$ and a second stream dominated by nitrogen is $0.15 \mathrm{MJ}_{\mathrm{e}} / \mathrm{kg} \mathrm{CO}_{2}$. The minimum work of compression from 1 to 150 bar is about 0.22 $\mathrm{MJ}_{\mathrm{e}} / \mathrm{kg} \mathrm{CO}_{2}$, for a total of about $0.37 \mathrm{MJ}_{\mathrm{e}} / \mathrm{kg} \mathrm{CO}_{2}$ captured when the heat rejection temperature and final $\mathrm{CO}_{2}$ temperature are $298.15 \mathrm{~K}$. Most of the alternative processes separate and produce $\mathrm{CO}_{2}$ at $35-40{ }^{\circ} \mathrm{C}$, in which case both the minimum separation and compression energies increase, with a total of about 0.38 to $0.42 \mathrm{MJ}_{\mathrm{e}} / \mathrm{kg}$ depending on assumptions ${ }^{7,8}$. Literature estimates from third-party sources regarding energy demands of practical systems typically range from 1-1.5 $\mathrm{GJ}_{\mathrm{e}}$ /tonne $\mathrm{CO}_{2}$ captured ${ }^{8-11}$, with the most recent US DOE estimates at the lower end of this range $^{8,12}$. These energy penalties indicate the equivalent amount of work required, regardless of whether the energy is actually electricity, heat, or a combination of each. The energy analyses in this work follow the methods and use the computer codes and assumptions of the published, detailed US DOE results ${ }^{9,11}$.

Oxy-combustion. This method of $\mathrm{CO}_{2}$ management uses a pre-combustion, cryogenic air separation unit that separates oxygen to combust with coal, resulting in nominally pure combustion products, $\mathrm{CO}_{2}$ and $\mathrm{H}_{2} \mathrm{O}$. The resulting flue gas cools, condensing $\mathrm{H}_{2} \mathrm{O}$, and then nominally pure $\mathrm{CO}_{2}$ is pressurized and sequestered or used for enhanced oil recovery. One fullscale power plant using this technology remains in consideration at White Rose (UK) while other major oxycombustion projects in the US and Europe lost support for a variety of reasons. 
Hurdles for widespread adoption of oxy-combustion include its high energy penalty due to the extreme, low temperatures $(\sim 73 \mathrm{~K})$ required for cryogenic distillation of $\mathrm{O}_{2}$ from air $^{13}$. The resulting energy penalty is in the range of $0.97-1.5 \mathrm{MJ}_{e} / \mathrm{kg} \mathrm{CO}_{2}$ captured $^{9,10,14,15}$. There is little expectation for reducing the energy penalty due to the constraints in the air separation unit with similar molecular weights and vapor pressures of $\mathrm{N}_{2}$ and $\mathrm{O}_{2}$.

Chemical Looping. Chemical looping poses a similar approach to $\mathrm{CO}_{2}$ management, but oxygen is introduced as part of an oxidized metal, such as iron titanium oxide ${ }^{16}$, instead of as a gas. Oxygen, typically from air, binds to the solid metal carrier in a fluidized bed, and then the oxidized solid metal flows to a second fluidized in which it reacts with fuel to reduce the metal oxide and oxidize the fuel. The reduced solid metal returns to the first fluidized bed to be reoxidized $^{17}$. The combustion products undergo treatment similar to those of oxy-combustion. Some of the most significant concerns with the chemical looping include the effects of thermally cycling the oxidizing metal carrier. Deactivation with use and entropy losses due to heating and cooling of the solid particles significantly affect the energy penalty. While chemical looping systems exist at atmospheric conditions, energy penalties for these systems were not found in literature and have not been provided in this review. The energy penalty associated with carbon capture by pressurized chemical looping is less than if it were applied to the near atmospheric combustion of this study's base power plant. Disregarding the energy for compression, the energy penalty range is $0.2-0.5 \mathrm{MJ}_{\mathrm{e}} / \mathrm{kg} \mathrm{CO}_{2}$ captured when applied to high-pressure combustion systems $^{18,19}$. Current research and development includes work at the National Carbon Capture Center on a $150 \mathrm{~kW}_{\mathrm{e}}$ equivalent system ${ }^{20}$. NETL provides a summary of several other chemical looping projects ${ }^{21}$. Because chemical looping requires replacing most of an existing power plant, chemical looping usually competes better as an option for new installations rather than as a retrofit option.

Absorbents. Amine scrubbing processes are by far the most widely used form of $\mathrm{CO}_{2}$ removal technology and have decades or industrial experience ${ }^{22}$. They are commercially available for multiple applications. Amine sorbents bind to the $\mathrm{CO}_{2}$, removing it from the process stream. The data from several literature sources show a large variation in energy penalties despite similar sorbent composition. They range from $0.97-4.20 \mathrm{MJ}_{\mathrm{e}} / \mathrm{kg} \mathrm{CO}_{2}{ }^{22-31}$ depending on the power plant and the design of the system. Generally, NETL reports an amine carbon capture system to have an associated energy penalty of $1.3 \mathrm{MJ}_{\mathrm{e}} / \mathrm{kg} \mathrm{CO}_{2}$ captured $^{10}$. Variations on compressors, pressures, percent sorbent, and the sorbent composition used are all major contributors to the energy penalties experienced by these processes ${ }^{27}$. A major benefit of this system is that it is a very mature system, at least in its traditional uses in natural gas conditioning $^{22}$. It is also commercially available for power plants, although many absorbents are not past the pilot scale. SaskPower's Boundary Dam integrated Carbon Capture and Sequestration project in Canada is the largest and first project of its type to demonstrate postcombustion capture on a commercial coal-fired power plant. The repowered 110-120 $\mathrm{MW}_{\mathrm{e}}$ power plant will produce about one million tons of captured $\mathrm{CO}_{2}$ per year, about $95 \%$ of its total output, much of which supplies enhanced oil recovery at the Weyburn oil field. It uses an aminebased solvent developed by Cansolv, a wholly owned subsidiary of Shell Oil Co. Additionally, a 
112 Southern Company is constructing a Selexol process for the full-scale Kemper power plant 113 (USA). Some drawbacks include the size of the process as well as the toxicity of the chemicals 114 and the energy cost to the system. Other amine-type sorbents include Fluor's Econamine system, 115 MHI's KS-1 solvent, and mixtures of primary, secondary, and tertiary amines. These sorbents, 116 while differing from each other, have approximately similar energy penalties to more traditional 117 MEA sorbents.

118 Other types of sorbents, such as Opticap by B \& W, have many drawbacks similar to 119 those mentioned for amines, but additionally have far less research supporting them and are not 120 as commercially available. They are, however, sometimes more efficient as shown by a 121 comparison conducted at NCCC, where Opticap proved significantly more efficient under similar 122 circumstances as $\mathrm{MEA}^{26}$.

Adsorbents. Due to the physical attraction between $\mathrm{CO}_{2}$ and other species, adsorbents find some uses for $\mathrm{CO}_{2}$ capture. Typical $\mathrm{CO}_{2}$ adsorbents include zeolites, molecular sieves, and activated carbon. These preferentially adsorb $\mathrm{CO}_{2}$ from air-fired combustion products. Once the adsorbent saturates with $\mathrm{CO}_{2}$, it generally regenerates with a pressure and/or temperature swing. The energy penalty of adsorbents depends primarily on the energy required for the cyclical change in conditions and is in the range of 2.0-5.6 $\mathrm{MJ}_{\mathrm{e}} / \mathrm{kg} \mathrm{CO}_{2}$ captured ${ }^{22,32}$. More advanced adsorbents remain under development in several research programs.

Membranes. Membranes provide an alternative to chemicals. Membranes can either provide pre-combustion enrichment of $\mathrm{O}_{2}$ or post-combustion $\mathrm{CO}_{2}$ separation from a flue gas. $\mathrm{CO}_{2}$ penetrates the membrane faster than other species, specifically $\mathrm{N}_{2}$. The membranes are commonly made from polymers ${ }^{33}$ and are sometimes made from other materials such as palladium ${ }^{34}$. The membrane selectively separates components in the stream, specifically the $\mathrm{CO}_{2}$ molecules. Testing of membranes remains at small scale compared to amine processes. The distinct advantage they have is the absence of toxic chemicals. Membrane separation requires replacement membranes ${ }^{35}$ as well as significant pumping power ${ }^{36}$, the latter resulting in energy penalties within the range of $0.95-1.9 \mathrm{MJ}_{\mathrm{e}} / \mathrm{kg} \mathrm{CO}_{2}$ captured $^{34,37}$. They also struggle to produce high purity $\mathrm{CO}_{2}$.

Cryogenic Processes. Cryogenic technologies come in several forms, including the thermal swing process, inertial carbon extraction system, and the CCC-ECL. A thermal swing process freezes $\mathrm{CO}_{2}$ as a solid directly on the surface of a heat exchanger. The heat transfer degrades with time as solid $\mathrm{CO}_{2}$ fouls the surface. At some point, a second parallel heat exchanger begins processing the stream while the first warms and regenerates ${ }^{38}$. In the case of 90 $\% \mathrm{CO}_{2}$ capture from a coal-fired power plant, Pan et al. report that the process energy penalty is $1.18 \mathrm{MJ}_{\mathrm{e}} / \mathrm{kg} \mathrm{CO}_{2}{ }^{39}$. Significant energy losses occur with the temperature swing of the heat exchanger. In addition, heat transfer rates reduce as $\mathrm{CO}_{2}$ solids form on the heat exchanger surfaces. The continual handling of $\mathrm{CO}_{2}$ solids is a major hurdle for adoption common among all of the cryogenic processes. Mechanical cleaning provides one means for handling the solids formation. While Alstom has generally been interested in this basic process, Shell has also 
investigated similar processes and shown good agreement between predictions and 152 experimentation ${ }^{40}$. Alstom has slowed the development of the thermal swing process because of

153 minor energy penalty improvements and major capital costs compared with conventional amine 154 systems.

Inertial Carbon Extraction System, an expansion process, forms solid $\mathrm{CO}_{2}$ without any of the surface fouling issues ${ }^{41}$. Flue gas is expanded through a nozzle, and solid $\mathrm{CO}_{2}$ particles form with the heat transfer coming from expansion rather than a surface. A cyclone separates the gas/solid stream. The design, operation, and maturity of this process are significant obstacles to commercialization.

The CCC-ECL likewise operates with the formation of $\mathrm{CO}_{2}$ solid particles at cryogenic temperatures. The CCC-ECL removes up to $99+\%$ of the $\mathrm{CO}_{2}$ from flue gas in a continuous process while maintaining a low energy penalty of $0.74 \mathrm{MJ}_{\mathrm{e}} / \mathrm{kg} \mathrm{CO}_{2}$. The technology works by cooling the flue gas to low temperatures, removing water before reaching $273 \mathrm{~K}$, and passing the gas through patented desublimating heat exchangers at temperatures near $150 \mathrm{~K}$. This causes desublimation of the $\mathrm{CO}_{2}$ to occur, leaving solid $\mathrm{CO}_{2}$ in a slurry. The solid $\mathrm{CO}_{2}$ separates from the contact liquid and melts under pressure as it warms back to room temperature. The advantages of this system include low energy penalty, grid-scale energy storage potential, process simplicity, low cost, multipollutant capture, and lack of toxic chemicals. $\mathrm{CO}_{2}$ solids formation is the major technical problem with this technology. This has the potential to plug and foul heat exchangers and otherwise complicate the process. Sustainable Energy Solutions (SES) has patented three heat exchangers that operated at steady state with no compromise in performance when treating solids-forming fluids. With lab-, bench- and skid-scale validations completed at scales up to 1 ton of $\mathrm{CO}_{2}$ per day, the technology is approaching pilot-scale in its development path. Process simulations using both Aspen Plus ${ }^{\mathrm{TM}}$ and an in-house SES code predict very similar results that compare favorably with alternative technologies. This paper presents simulation results with Aspen Plus ${ }^{\mathrm{TM}}$.

\section{CCC-ECL PHASE EQUILIBRIUM MODELS}

The limited solid liquid vapor equilibrium (SLVE) calculated by the Peng-Robinson equation of state (PR-EOS) predicts the equilibrium achieved in a desublimation column. SLVE involves iteration and in these cases uses Raoult's Law for generating initial estimates. Equilibrium predictions assume that (1) no $\mathrm{CO}_{2}$ liquid phase exists below its freezing point and (2) the solid phase is pure $\mathrm{CO}_{2} \cdot \mathrm{CO}_{2}$ dissolution in other liquids is included.

Predictions depend heavily on solid- $\mathrm{CO}_{2}$ vapor pressure. New parameters for solid- $\mathrm{CO}_{2}$ vapor pressure correlations resulted from this investigation and based on least squares analyzes of several sources of $\mathrm{CO}_{2}$ sublimation data. Table 1 summarizes the sources of solid- $\mathrm{CO}_{2}$ vapor pressure data. Parameters comparisons for several empirical vapor pressure equations (Antoine, Riedel, Wagner, Span and Wagner ${ }^{42}$ ) indicate that the Riedel and Wagner equations having the 
188 smallest sum of squared errors. The 5-parameter Riedel equation with newly regressed 189 parameters fit well with temperatures above $150 \mathrm{~K}$, but has significant deviations at lower 190 temperatures. The region of interest is from the triple point to processing temperatures around $191150 \mathrm{~K}$ for $90 \%$ carbon capture. A $6^{\text {th }}$ parameter inside the exponential, $\frac{F}{T^{2}}$, improved the fit better 192 than a variety of other options. The 6-parameter correlation is

$$
P_{C O_{2}}^{s u b}=\exp \left[57.52+\frac{-3992.84}{T}-4.9003 \cdot \ln (T)+2.415 \cdot 10^{-15} \cdot T^{6}+\frac{8125.6}{T^{2}}\right]
$$

194 where $T$ is the temperature in $\mathrm{K}$ and $P_{\mathrm{CO}_{2}}^{s u b}$ is the solid vapor pressure of $\mathrm{CO}_{2}$ in Pa. Figure 1 195 compares the improvement in predicted residuals with DIPPR and NIST correlations of the 196 Riedel forms in the temperature region of interest.

197

Table 1 Summary of published solid- $\mathrm{CO}_{2}$ vapor pressure measurements

\begin{tabular}{llll}
\hline $\begin{array}{l}\text { \# of Data } \\
\text { Points }\end{array}$ & $\begin{array}{l}\text { Temperature } \\
{[\mathbf{K}]}\end{array}$ & $\begin{array}{l}\text { Pressure } \\
{[\text { Pa] }}\end{array}$ & Reference \\
\hline 62 & $69-103$ & $7 \cdot 10^{-8}-0.05$ & Bryson et al. $^{43}$ \\
11 & $106-154$ & $0.1-1,334$ & Tickner \& Lossing $^{44}$ \\
7 & $138-195$ & $133-100,000$ & Stull $^{45}$ \\
8 & $140-195$ & $200-101,000$ & Kaye \& Laby $^{46}$ \\
20 & $153-204$ & $1,333-200,000$ & Thermodynamic Research Center $^{47}$ \\
6 & $154-196$ & $1,509-111,000$ & Giauque \& Egan $^{48}$ \\
131 & $154-217$ & $1,490-527,000$ & Bilkadi et al. $^{49}$ \\
16 & $178-198$ & $23,700-131,000$ & Ambrose $^{50}$ \\
19 & $192-195$ & $86,000-102,000$ & Heuse \& Otto $^{51}$ \\
21 & $194-217$ & $97,700-517,000$ & Fernandez-Fassnacht \& Del Rio $^{52}$ \\
28 & $194-217$ & $99,000-518,000$ & Meyers \& Van Dusen $^{53}$ \\
1 & 195 & 101,325 & Mullins et al. $^{54}$ \\
1 & 195 & 101,325 & Marsh $^{55}$ \\
6 & $201-213$ & $179,000-385,000$ & Baughman et al. $^{56}$ \\
\hline
\end{tabular}

199 


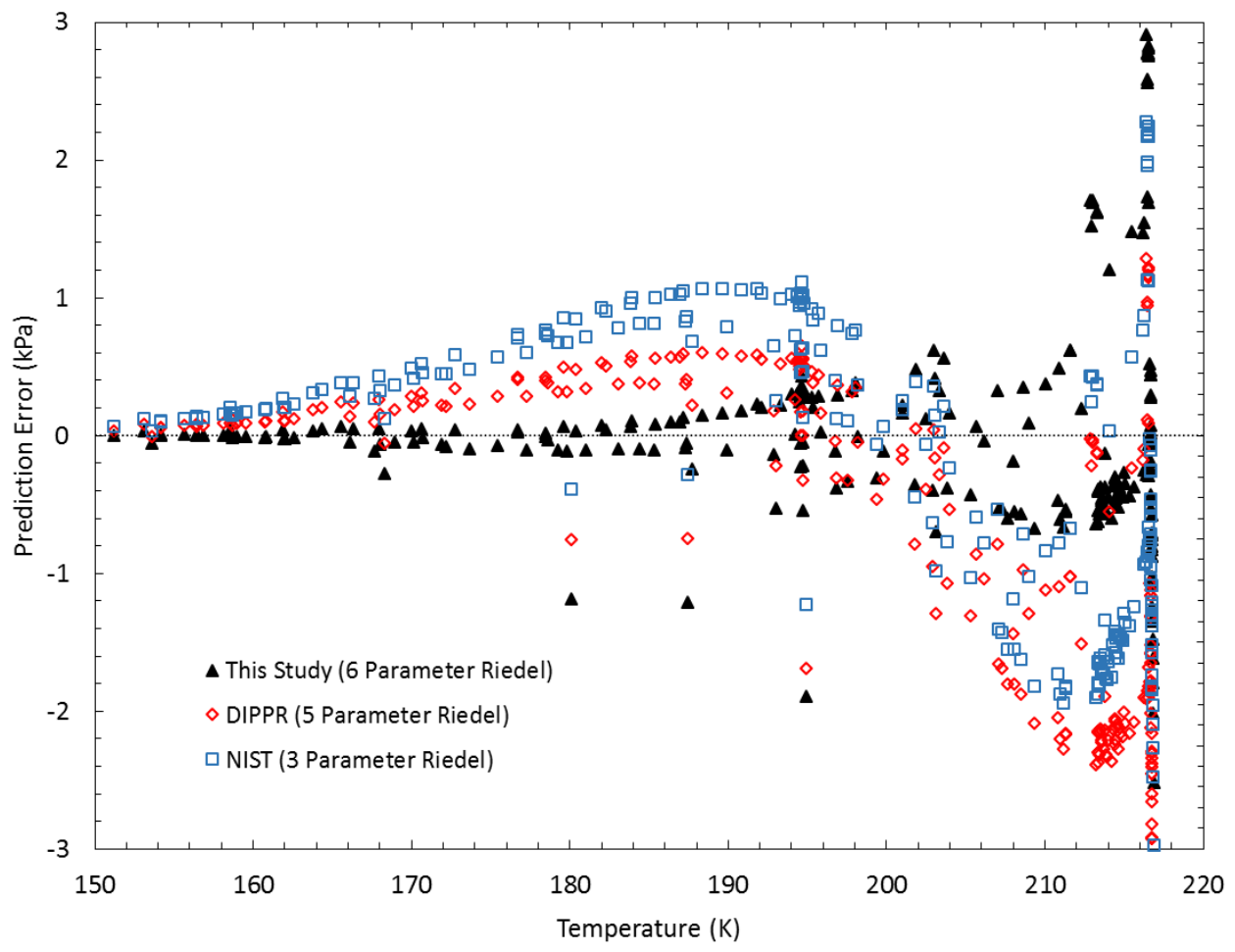

Figure 1 Residuals of solid-CO $\mathrm{CO}_{2}$ vapor pressure with correlations from DIPPR $^{57}$ \& NIST $^{58}$

Raoult's law provides a starting point for estimating $\mathrm{CO}_{2}$ phase equilibrium for vapor and solid phases. Raoult's law, applied to $\mathrm{CO}_{2}$ sublimation, is

where $x_{\mathrm{CO}_{2}}$ and $y_{\mathrm{CO}_{2}}$ are the mole fractions of $\mathrm{CO}_{2}$ in the condensed (solid) and vapor phases respectively, $P_{\mathrm{CO}_{2}}^{\mathrm{Sub}}$ is the sublimation vapor pressure of $\mathrm{CO}_{2}$, and $P$ is the total pressure. Donnelly and Katz reported that the melting point of the solid found in equilibrium with the vapor and liquid was the same as pure carbon dioxide, indicating that the $\mathrm{CO}_{2}$ forms an essentially pure solid phase ${ }^{59}$, so $x_{\mathrm{CO}_{2}}=1$. Therefore, Raoult's law predicts the mole fraction of $\mathrm{CO}_{2}$ in the vapor phase as a function of temperature and total pressure (Eqn. 3) as

$$
y_{C o_{2}}=\frac{P_{C O_{2}}^{s u b}(T)}{P}
$$

A Poynting correction factor and non-ideal fluid models improve SLVE equilibrium 215 liquid phase. $\mathrm{CO}_{2}$ does form in the liquid phase, but this does not appreciably affect the vapor concentration. Thus, solutions simultaneously predict $\mathrm{SVE}$ for $\mathrm{CO}_{2}$ and VLE for all other components. These equilibria, are expressed, respectively, by 


$$
\begin{gathered}
\emptyset_{C O_{2}}^{\text {sub }} \cdot P_{C O_{2}}^{\text {sub }} \cdot e^{\frac{V_{C O_{2}}^{\text {solid. }\left(P-P_{C O_{2}}^{\text {sub }}\right)}}{R \cdot T}}=y_{C O_{2}} \cdot \bar{\emptyset}_{C O_{2}}^{\text {vap }} \cdot P \\
\bar{\emptyset}_{i}^{\text {liq }} \cdot P_{i}^{\text {vap }} \cdot e^{\frac{v_{i}^{\text {liquid }} \cdot\left(P-P_{i}^{v a p}\right)}{R \cdot T}}=y_{i} \cdot \bar{\emptyset}_{i}^{\text {vap }} \cdot P
\end{gathered}
$$

where $i$ is the component, $\emptyset_{i}$ is the fugacity coefficient of $i$ at the saturated solid/liquid pressure or total pressure for the vapor, the over bar on fugacity coefficients denotes a partial fugacity coefficient, $V_{i}$ is the solid/liquid molar volume, and $R$ is the universal gas constant. The liquidphase $\mathrm{CO}_{2}$ that forms due to solubility is not predicted because the liquid recirculates back into the desublimation column. While the CCC-ECL process does not operate at significant pressure, the Poynting correction factor term is included because the validation uses some high-pressure data. The Peng-Robison equation of state (PR-EOS) estimates the fugacity coefficients, which approach unity at low pressure and high purity. Because the fugacity coefficients are functions of composition, the solutions are iterative.

The generalized form of the PR-EOS ${ }^{60}$ is

$$
P=\frac{R \cdot T}{V_{m}-b}-\frac{a(T)}{V_{m}\left(V_{m}+b\right)+b\left(V_{m}-b\right)}
$$

where $V_{m}$ is the molar volume, $T_{c}$ is the critical temperature, $P_{c}$ is the critical pressure, and $\omega$ is the acentric factor.

$$
a(T)=0.45724 \frac{R^{2} \cdot T_{c}^{2}}{P_{c}}\left[1+\kappa\left[1-\sqrt{\frac{T}{T_{c}}}\right]\right]^{2}
$$

$$
b=0.07780 \frac{R \cdot T_{c}}{P_{c}}
$$

$$
\kappa=0.37464+1.54226 \omega-0.26992 \omega^{2}
$$

For the PR-EOS, the fugacity coefficient (Eqn. 10) depends on the compressibility (Eqns. 11-13) with classic mixing/combining rules (Eqns. 14-15).

$$
\begin{gathered}
\ln \left(\bar{\emptyset}_{i}\right)=Z-1-\ln (Z-B)-\frac{A}{2 \sqrt{2} B} \ln \left(\frac{Z+(1+\sqrt{2}) B}{Z+(1-\sqrt{2}) B}\right) \\
Z^{3}-(1-B) Z^{2}+\left(A(T)-3 B^{2}-2 B\right) Z-\left(A(T) \cdot B-B^{2}-B^{3}\right)=0 \\
A(T)=\frac{a(T) \cdot P}{R^{2} \cdot T^{2}} \\
B=\frac{b \cdot P}{R \cdot T} \\
a(T)=\sum_{i=1}^{N} \sum_{j=1}^{N} x_{i} x_{j} \sqrt{a(T)_{i} a(T)_{j}}\left(1-k_{i j}\right) \\
b=\sum_{i=1}^{N} x_{i} b_{i}
\end{gathered}
$$


where $Z$ is the compressibility and $k_{i j}$ is the binary interaction parameter.

Several data reviews estimate the thermodynamic parameters for the PR-EOS. This simulation uses the Aspen Plus' Pure APV80 database values along with the proposed solid vapor pressure correlation. Available thermodynamic data from NIST and DIPPR are widely accepted, but are generally limited to pure-component vapor/liquid data. Comparisons of the available data and predictions discussed below assure that PR-EOS parameters properly predict solid phase formation.

\section{Validation of Prediction Methods}

Literature data are not available for equilibrium conditions of flue gas and solid $\mathrm{CO}_{2}$. However, from the natural gas processing industry, $\mathrm{CO}_{2}$ frost-point temperatures are extremely important and many groups report them. These measured frost-point temperatures provide a means validating with predictions to determine the applicability of the presented equilibrium methods. Table 2 summarizes the $\mathrm{CO}_{2}$ frost-point temperature data. The goodness of fit or correlation is reported by the bias, average absolute deviation (AAD) and mean square error (MSE), defined as

where $n$ is the number of data points in the data set, $T_{\text {calc }}$ is the predicted frost-point temperature, and $T_{\text {exp }}$ is the experimentally determined frost-point temperature. The new solid vapor pressure correlation makes a $0.2 \mathrm{~K}, 0.3 \mathrm{~K}$, and $2.3 \mathrm{~K}^{2}$ improvement in bias, AAD, and MSE, respectively, for predictions with the PR EOS compared to best published solid-vaporpressure correlation of which we are aware, DIPPR.

Table 2 Summary of published $\mathrm{CO}_{2}$ frost-point measurements with prediction goodness quantified by bias, AAD, and MSE for the PR EOS

\begin{tabular}{|c|c|c|c|c|c|c|c|c|c|c|c|c|c|}
\hline \multirow[b]{2}{*}{ Data } & \multirow[b]{2}{*}{$\begin{array}{l}\text { Temp } \\
{[\mathrm{K}]}\end{array}$} & \multirow[b]{2}{*}{$\begin{array}{l}\text { Pressure } \\
{[\mathrm{kPa}]}\end{array}$} & \multirow[b]{2}{*}{$\begin{array}{l}\text { Composition } \\
{\left[\% \text {, balance } \mathrm{CH}_{4}\right]}\end{array}$} & \multicolumn{3}{|c|}{$\begin{array}{c}\text { Aspen Plus } \\
\text { Bias AAD MSE }\end{array}$} & \multicolumn{3}{|c|}{ DIPPR } & \multicolumn{3}{|c|}{ New } & \multirow[b]{2}{*}{ Reference } \\
\hline & & & & $\begin{array}{r}\text { Bias } \\
{[\mathrm{K}]}\end{array}$ & $\begin{array}{c}\text { AAD } \\
{[\mathbf{K}]}\end{array}$ & $\begin{array}{l}\text { MSE } \\
{\left[\mathbf{K}^{2}\right]}\end{array}$ & $\begin{array}{c}\text { Bias } \\
{[\mathbf{K}]}\end{array}$ & $\begin{array}{c}\text { AAD } \\
{[\mathbf{K}]}\end{array}$ & $\begin{array}{l}\text { MSE } \\
{\left[\mathbf{K}^{2}\right]}\end{array}$ & $\begin{array}{r}\text { Bias } \\
{[\mathbf{K}]}\end{array}$ & $\begin{array}{l}\mathbf{A A D} \\
{[\mathbf{K}]}\end{array}$ & $\begin{array}{l}\text { MSE } \\
{\left[\mathrm{K}^{2}\right]}\end{array}$ & \\
\hline \multicolumn{14}{|c|}{ Frost-Point Measurements of Binary Systems } \\
\hline 42 & 137-198 & $179-2785$ & $0.1-10.7 \mathrm{CO}_{2}$ & -1.4 & 2.0 & 5.5 & -1.1 & 1.8 & 4.6 & -0.8 & 1.6 & 3.8 & Agrawal $^{61}$ \\
\hline 75 & $132-210$ & $156-4790$ & $0.03-59 \mathrm{CO}_{2}$ & -0.6 & 0.7 & 1.0 & -0.2 & 0.4 & 0.5 & -0.1 & 0.4 & 0.2 & Pikaar $^{62}$ \\
\hline 17 & $191-210$ & $293-4446$ & $10.8-54.2 \mathrm{CO}_{2}$ & -0.2 & 0.7 & 0.6 & -0.1 & 0.7 & 0.6 & -0.1 & 0.7 & 0.6 & Zhang $^{63}$ \\
\hline 39 & $170-200$ & $689-2413$ & $2-16 \mathrm{CO}_{2}$ & -1.4 & 1.4 & 2.4 & -1.2 & 1.2 & 1.7 & -1.2 & 1.2 & 1.6 & GPSA $^{64 \text { A }}$ \\
\hline 47 & $168-185$ & $962-2464$ & $1-2.9 \mathrm{CO}_{2}$ & 0.4 & 2.3 & 6.9 & 0.8 & 2.4 & 14.7 & 1.0 & 2.5 & 8.4 & $\mathrm{Le}^{65}$ \\
\hline 11 & $130-201$ & 5000 & $0.2-20.5 \mathrm{CO}_{2}$ & -5.0 & 5.0 & 57.5 & 3.7 & 3.7 & 39.9 & 5.3 & 5.3 & 39.6 & Kurata $^{66 \mathrm{~A}}$ \\
\hline
\end{tabular}


Frost-Point Measurements of Ternary Systems

\begin{tabular}{rlllllllllllll}
19 & $154-172$ & $172-2441$ & $0.9 \mathrm{CO}_{2} \& 0.7-2.9 \mathrm{~N}_{2}$ & -1.7 & 1.7 & 3.4 & -1.3 & 1.4 & 2.4 & -0.9 & 1.1 & 1.6 & Agrawal $^{61}$ \\
24 & $174-184$ & $1243-2262$ & $1.9 \mathrm{CO}_{2} \& 96-97 \mathrm{~N}_{2}$ & -0.4 & 1.7 & 3.7 & -0.3 & 1.6 & 15.2 & -0.1 & 1.6 & 3.4 & Le $^{65}$ \\
\hline
\end{tabular}

${ }^{\mathrm{A}}$ reported by ZareNezhad

Figure 2 compares the frost-point predictions using Raoult's law with measurements. Pikaar's data highlights the inadequacy of Raoult's law for high-pressure predictions. At low pressures, fugacity coefficients approach unity, but for the case of high-pressure measurements, 273 the fugacity coefficient of the vapor phase deviates from unity. Figure 3 and Figure 4 show frostpoint predictions with PR and SRK EOS, which account for the non-ideality at higher pressures and improve the agreement between predictions and measurements. Frost-point predictions generally fall within $3 \mathrm{~K}$ for both EOS, except for the measurements of Kurata, which are the highest pressure data at $5 \mathrm{MPa}$. The residuals of Le's measurements in binary systems trend with pressure and are thus suspicious. Otherwise, for both the PR and SRK EOS the predictions are generally within $\pm 3 \mathrm{~K}$.

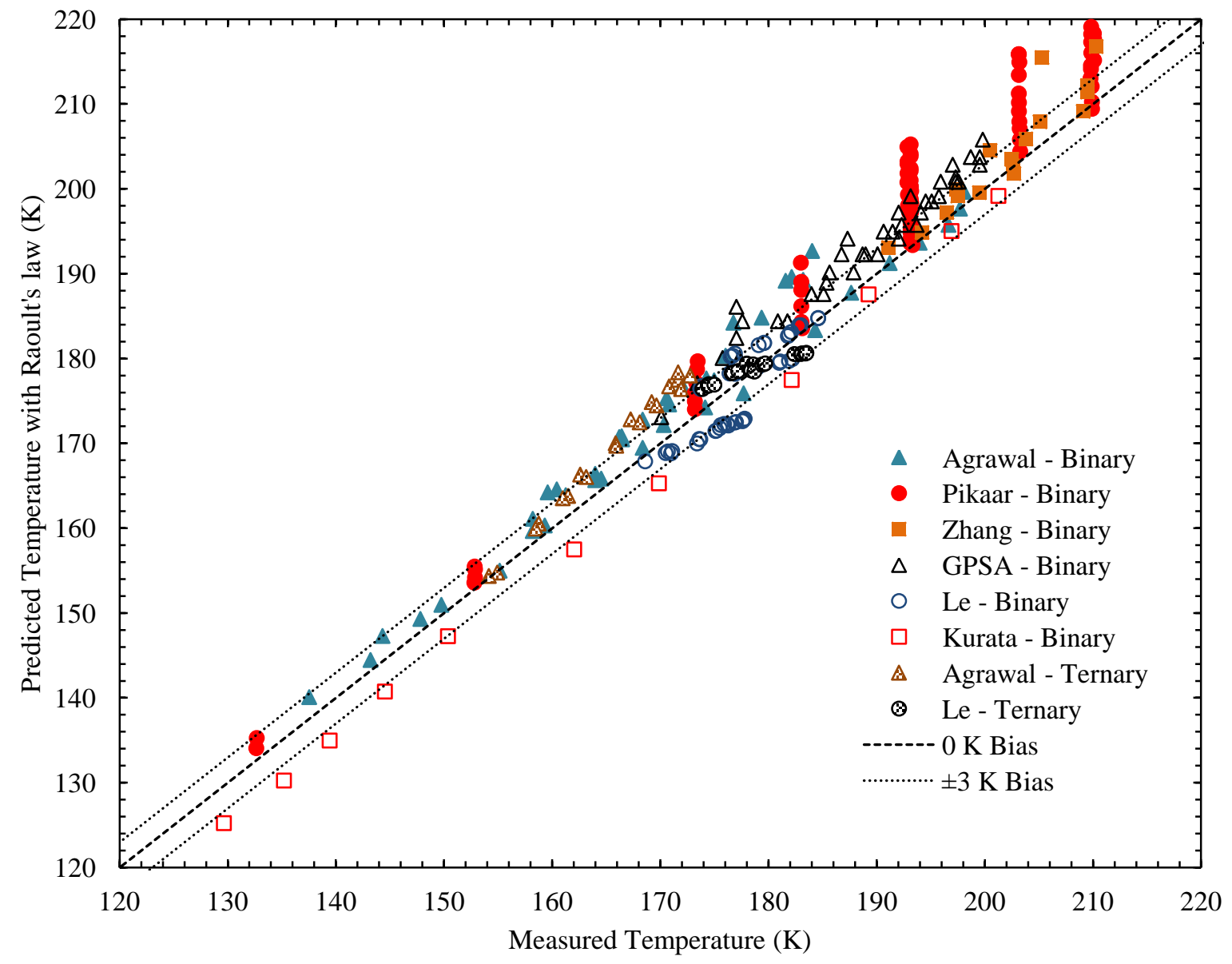
binary and ternary systems 


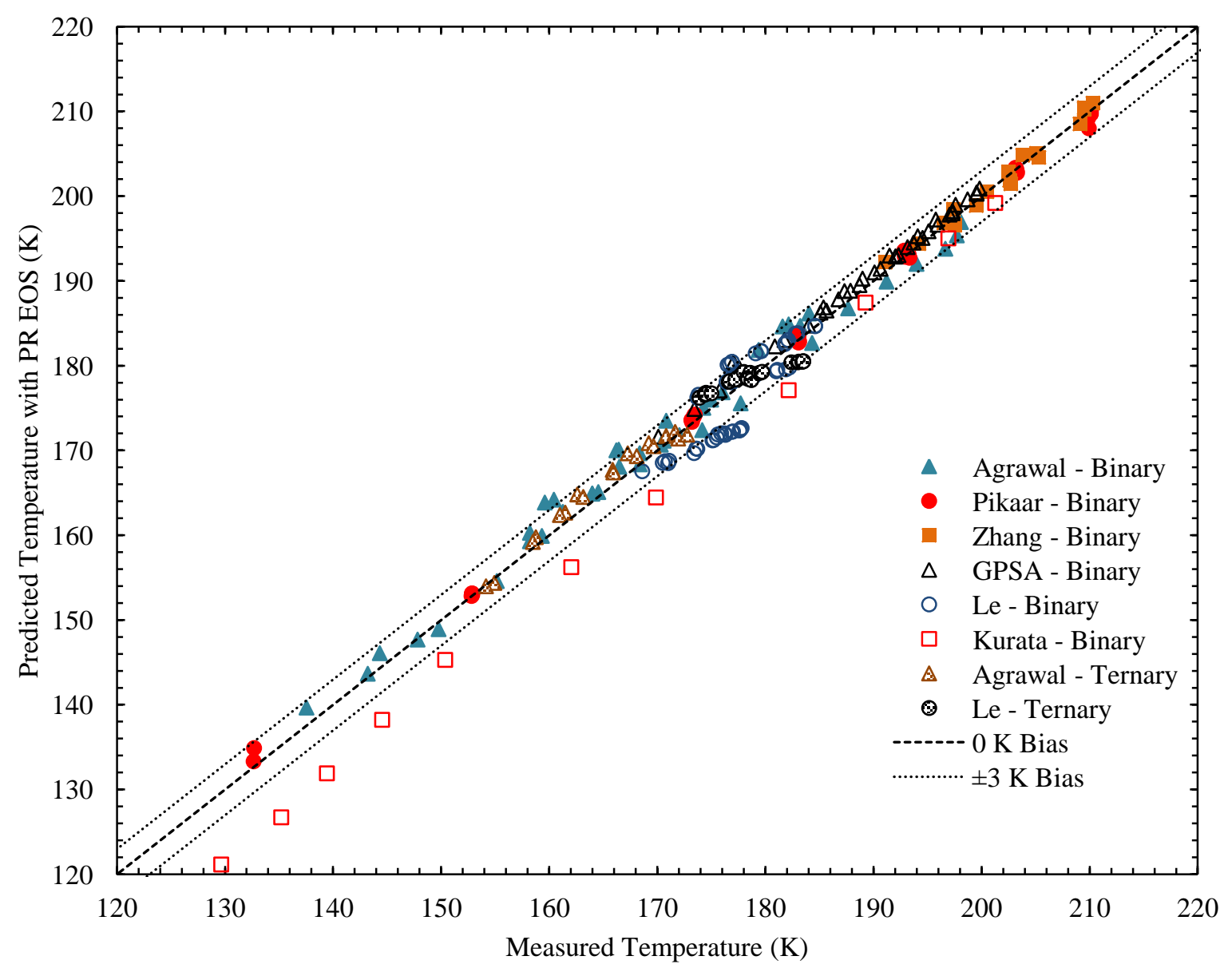
and ternary systems 


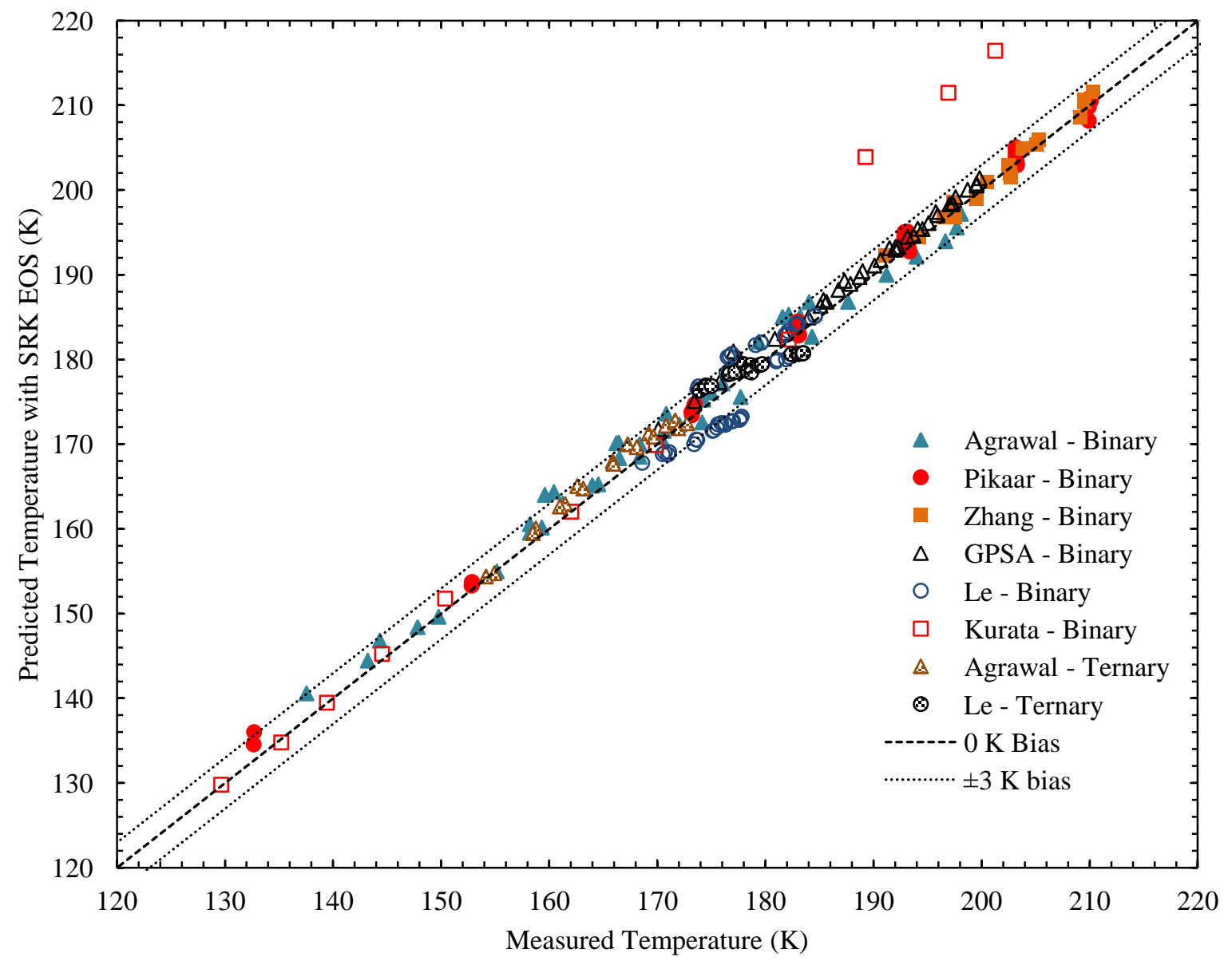

Figure 4 Frost-point temperature predictions with SRK EOS vs. measurements for binary and ternary systems

Several experimental apparatuses demonstrate the basic functionality of CCC-ECL at lab294 and bench-scales. Flue gas flowrates vary between $0.02-1.4 \mathrm{~m}^{3} / \mathrm{min}$ for the different scales. 295 Figure 5 outlines the basic flow of the apparatuses. The first generation apparatus allowed visual 296 verification of performance in the desublimating column ${ }^{67}$ and had simpler materials for 297 construction, making testing of multiple design iterations simpler. The optical access provides 298 highly useful, but qualitative, information during its operation. The visual verification of the 299 desublimating column performance was extremely important in the first attempted experimental 300 runs to ensure proper operation and generating relevance between operation and measured 301 process parameters. Later apparatuses performed better and operated longer at the expense of 302 visual access. 


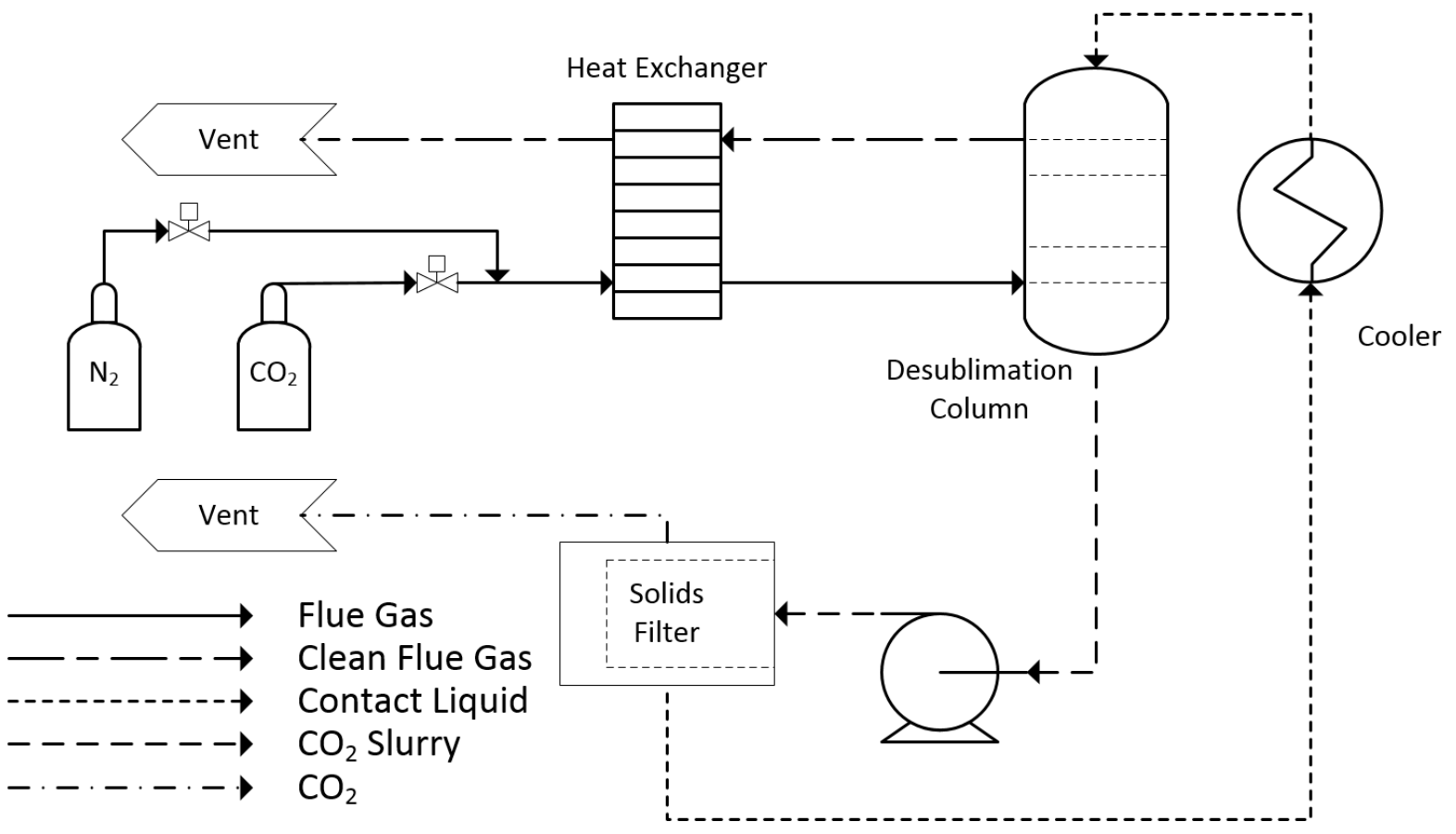

Figure 5 Simplified diagram of testing apparatus

The visually accessible desublimating column exterior surface comprises two vacuumseparated concentric acrylic tubes. Internal stages of perforated Teflon sheeting create bubbles in

307 a manner similar to sieve plates in conventional distillation. Stainless steel provides structural 308 rigidity, a weir, and a downcomer. O-rings seal the stages against the exterior and the steel frame 309 provides stage separation and support, see Figure 6. The acrylic construction and vacuum-sealed 310 walls are for experimental convenience. Subsequent desublimation columns were designed 311 similarly to the visually accessible desublimating column, but with stainless steel construction. 312 The columns were generally insulated by at least 6 inches of expanded perlite. Future designs of 313 contacting and non-contacting desublimation heat exchangers have been proposed and include a 314 spray tower and fluidized bed ${ }^{68}$. 

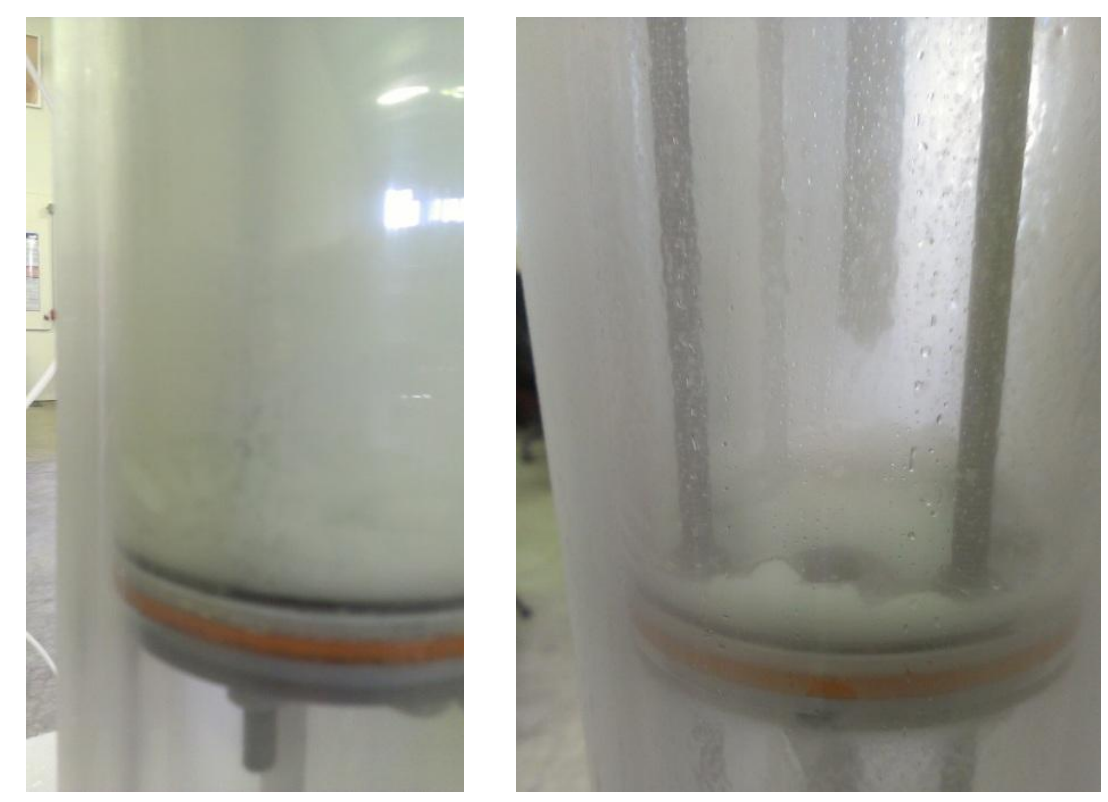

Figure 6 Single stage of heat exchanger a) during operation with solid $\mathrm{CO}_{2}$ particles suspended in contact liquid and b) post-operation, drained, with solid $\mathrm{CO}_{2}$ remaining

Similarly for all apparatuses, heat exchangers are stainless steel brazed-plate styles (Duda

Diesel, Pex Universe, \& GEA-PHE). Pressure transducers (Transducers Direct) were calibrated with factory certification of $0.25 \%$ accuracy. Thermocouples (Omega) have an uncertainty of \pm 1 K. Mass flow controllers (Omega \& Brooks) provide an arbitrary simulated flue gas composition, with the focus of this paper being a 85/15 mixture from cylinders (Airgas) containing $99.998 \%$ pure $\mathrm{N}_{2}$ and $99.5 \%$ pure $\mathrm{CO}_{2}$. Data was recorded by either a LabView compatible DAQ (National Instruments) or Simatics DCS (Siemens).

Three different gas analyzers measure $\mathrm{CO}_{2}$ concentrations as experimentation progressed. A non-dispersive infrared (NDIR) M-700 emissions analyzer (Enerac) has a limited resolution of $0.1 \%$. A $5975 \mathrm{C}$ quadrupole mass spectrometer (Agilent Technologies) provides additional gas analysis, specifically (1) verifying the adequacy of $\mathrm{CO}_{2}$ measurements of NDIR analyzers and (2) quantifying the trace elements (i.e. contacting liquid). For portable skids, an industrial ABB EL3040 analyzer provides continuous results with an increased resolution compared to the M$700(0.006 \%)$. The EL3040 also uses NDIR techniques and is limited to the $\mathrm{CO}_{2}$ concentration range of 0-3\%. Analyzers are calibrated with NIST-traceable Mesa Specialty gases and with inhouse calibration gases. In-house calibration gases are volumetrically made in a $1 \mathrm{~L}$ syringe (SGE).

Solid separation occurs in a semi-continuous batch strainer, hydrocyclone, and continuous filter press. The batch strainers are simple in design and operation, but are constrained to semi-continuous batch operation. While the molecular sieve used to dry the flue gas has similar batch-wise operation, it does not undergo large cryogenic temperature swings to 
340 expel the water. Considering the cost of refrigeration, a temperature-swing strainer has a 341 significant, detrimental effect on the energy penalty. To provide for continuous operation, a 342 hydrocyclone and a continuous filter press operate in series. The hydrocyclone is of typical 343 design and operation. The continuous filter press is auger driven, with special considerations 344 given to the properties of the solid $\mathrm{CO}_{2}$ particles. The resulting separation achieved in bench345 scale experiments is $2.6 \%$ of the contact liquid remaining in the solid $\mathrm{CO}_{2}$. To achieve the 346 separation necessary for $99.94 \%$ recovery of contact liquid, a standard flash drum is used after 347 the solid $\mathrm{CO}_{2}$ stream melts and warms. With the addition of the flash drum, less than $0.1 \%$ of 348 the contact liquid remains in the stream, and the $\mathrm{CO}_{2}$ meets specifications for EOR and 349 sequestration.

350 The most significant energy consumption in the CCC-ECL process involves refrigeration. 351 Previously, the equilibrium predictions by PR-EOS were presented with validation of $\mathrm{CO}_{2}$ frost352 point temperatures in binary and ternary mixtures composed primarily of $\mathrm{CH}_{4}$. The operability 353 and thermodynamic predictions of solid $\mathrm{CO}_{2}$ formation were validated by experiments ranging in 354 scale from synthetic flue gas flow rates of $0.02-1.4 \mathrm{~m}^{3} / \mathrm{min}$ (i.e., up to a $20 \mathrm{~kW}_{\mathrm{e}}$ equivalent 355 retrofit plant). Figure 7 shows the experimental measurements of an hour-long run at $1.4 \mathrm{~m}^{3} / \mathrm{min}$. 356 The prediction uses the PR-EOS with uncertainties from temperature and pressure 357 measurements. The EL3040 recorded $\mathrm{CO}_{2}$ concentration and the target $0.2 \% \mathrm{CO}_{2}$ in the exit gas 358 represents $98.7 \% \mathrm{CO}_{2}$ capture. The prediction adequately describes the highly varied $\mathrm{CO}_{2}$ 359 capture performance for the entire 85 minutes. Changes in operating conditions caused the other 360 peaks before 85 minutes. Steady operation with the same equipment meets target capture of 90+ $361 \%$ continuously but does not test the model accuracy over a range of flow conditions. The 362 experimental results from this and many other runs validate the ability of the PR-EOS to describe 363 the conditions necessary for full-scale demonstration of solid $\mathrm{CO}_{2}$ formation in the CCC-ECL 364 process. 


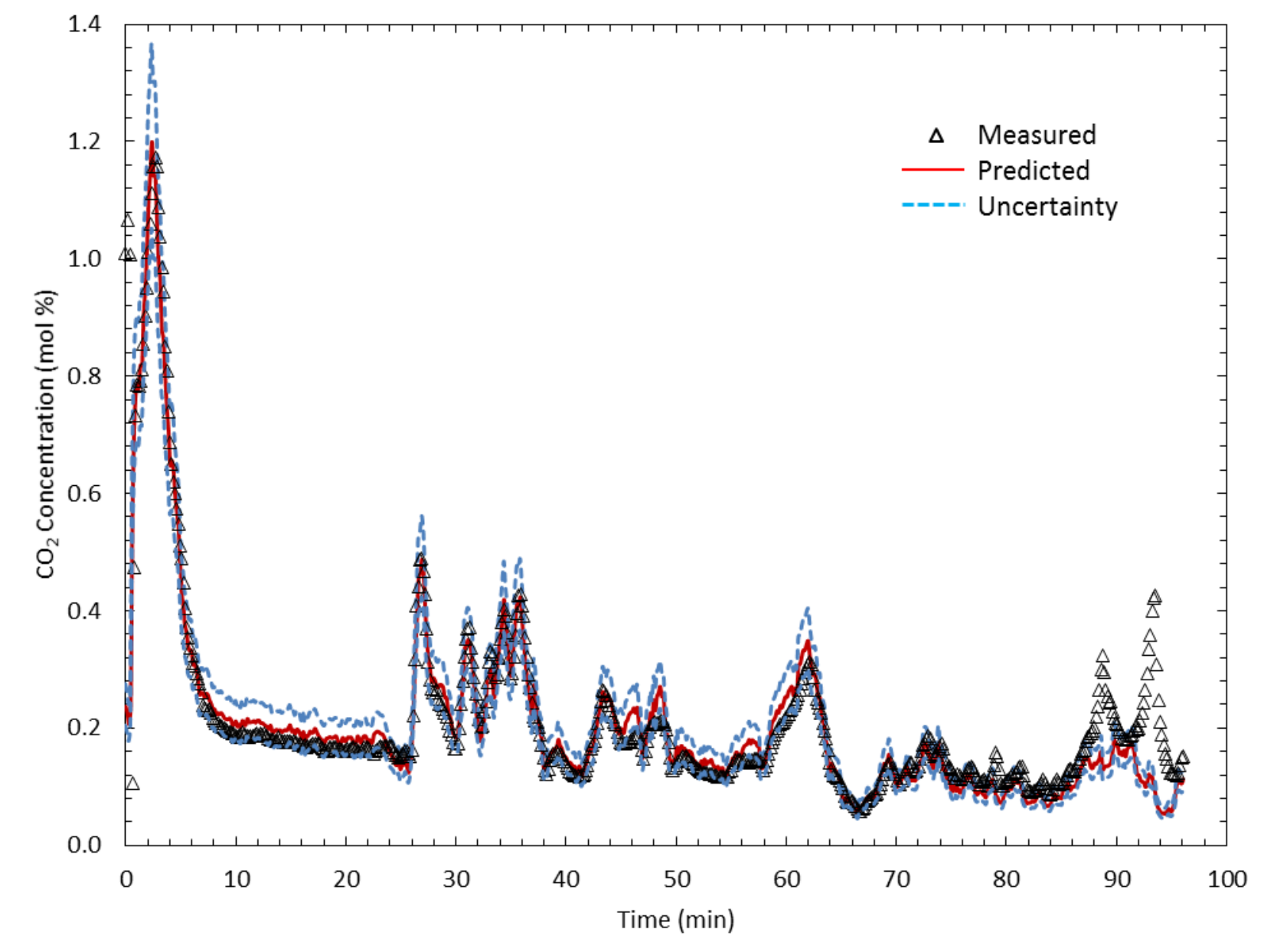

Figure 7 Experimental results of $\mathrm{CO}_{2}$ concentration in exiting flue gas while operating near atmospheric pressure and $133-153 \mathrm{~K}$ with inlet composition of $15 \% \mathrm{CO}_{2}$, balance $\mathbf{N}_{2}$

This embodiment of the CCC process provides a retrofit option to remove $90+\%$ of the $\mathrm{CO}_{2}$ from the flue gas of a coal-fired power plant. The following calculations assume a $550 \mathrm{MW}_{\mathrm{e}}$ net output prior to addition of $\mathrm{CO}_{2}$ capture. The cryogenic carbon capture cools the treated power plant's flue gas to $175 \mathrm{~K}$. The $\mathrm{CO}_{2}$ in the flue gas forms solid particles as the flue gas further cools to $154 \mathrm{~K}$ in a staged column with direct cryogenic liquid contact. The clean flue gas warms against the incoming flue gas and vents to the atmosphere. The $\mathrm{CO}_{2} /$ contacting liquid slurry undergoes filtration and subsequently the nearly pure solid warms to $233 \mathrm{~K}$ and provides a $\mathrm{CO}_{2}$ rich product. The $\mathrm{CO}_{2}$ liquefies and leaves the process prepared for enhanced oil recovery (EOR) or sequestration. All contacting liquid streams cool and recycle back to the staged column. An internal refrigeration cycle with $\mathrm{CF}_{4}$ transfers heat from melting $\mathrm{CO}_{2}$ to desublimating $\mathrm{CO}_{2}$. An 
external cooling loop of natural gas provides the additional heat duty to operate the cryogenic process. The streams and equipment discussions appear separately below. Figure 8 shows a simplified process flow schematic.

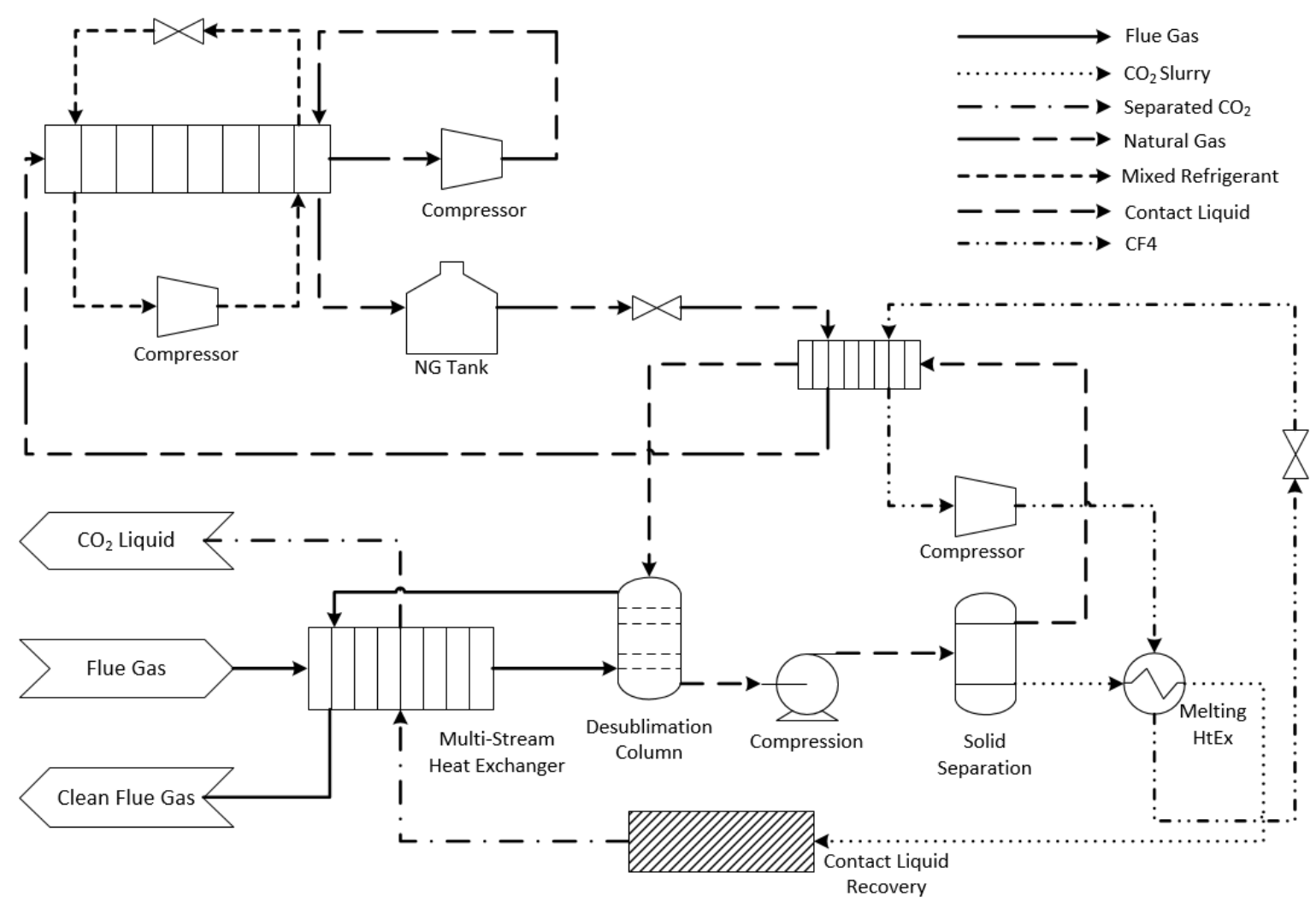

Flue Gas. Due to the potential formation of sulfuric acid and solid sulfur products, the $\mathrm{CCC}$ process uses gas after the power plant's flue gas desulfurization unit (FGD). The CCC process has demonstrated potential as a $\mathrm{SO}_{\mathrm{x}}, \mathrm{NO}_{\mathrm{x}}, \mathrm{Hg}, \mathrm{PM}_{\mathrm{xx}}$, and $\mathrm{HC}$ removal device as well as a $\mathrm{CO}_{2}$ mitigation system, and this has been demonstrated many times to be very efficient, but the focus here is on $\mathrm{CO}_{2}$. The flue gas from the FGD includes $2.4 \% \mathrm{O}_{2}, 68.08 \% \mathrm{~N}_{2}, 13.53 \% \mathrm{CO}_{2}$, $15.17 \% \mathrm{H}_{2} \mathrm{O}$, and $0.82 \% \mathrm{Ar}$ at $330.15 \mathrm{~K}$ and $102.042 \mathrm{kPa}$. Cooling the gas to $290 \mathrm{~K}$ condenses approximately $90 \%$ of the water. To overcome subsequent pressure drops, a blower pressurizes the flue gas to $127.6 \mathrm{kPa}$. The flue gas cools to near $273 \mathrm{~K}$ and regenerating mol sieve beds remove the residual water to ensure no ice formation as the flue gas cools in a multi-stream heat exchanger to $175 \mathrm{~K}$. The cooled flue gas enters the bottom of a 10-stage desublimating column and bubbles up through the tower while being cooled to $154 \mathrm{~K}$ by direct contact with a countercurrent contacting liquid. The cleaned flue gas leaves the top of the heat exchanger with less than 
$\mathrm{K}$ ), and experiments and theory demonstrate this. However, this simulation uses the DOE benchmark of $90 \% \mathrm{CO}_{2}$ capture. The separated gas recuperatively warms against incoming flue gas. Before the light gas stream returns to the stack, it augments an evaporative cooler to cool process water to near freezing temperatures.

Contact Liquid. The contact liquid is in a closed loop with minor losses into the $\mathrm{CO}_{2}$ byproduct and the light flue gas. In general, contacting liquids should have low vapor pressures to decrease losses through evaporation and otherwise be environmentally and physically benign. The contact liquid prevents $\mathrm{CO}_{2}$ solids from forming on surfaces and greatly simplifies solid $\mathrm{CO}_{2}$ transport as a slurry, thus preventing process freeze up. At its coldest temperature of $154 \mathrm{~K}$, the contact liquid enters the top stage of a desublimating column and cools the flue gas through direct contact, leaving the bottom stage as a slurry with solid $\mathrm{CO}_{2}$ entrained in the flow. A pump pressurizes the slurry prior to entering a solid-liquid separator. The separator consists of an auger-driven continuous filter press. The bulk contact liquid, now free of solids, re-cools against a closed-loop refrigeration system in preparation to reenter the desublimating column. Contact liquid recovered from the $\mathrm{CO}_{2}$-rich stream returns to the process. To counter the minor losses, a makeup stream of pressurized contacting liquid cools from ambient temperature.

Vapor pressure data for contacting liquids are commonly not available at these operating conditions. Experimental vapor pressure measurements ensure compliance with hydrocarbon emission standards.

$\mathbf{C F}_{4}$ Refrigeration. The $\mathrm{CF}_{4}$ refrigeration loop moves the cooling duty of melting $\mathrm{CO}_{2}$ melting to the colder temperature of desublimating $\mathrm{CO}_{2}$. After condensing against the melting $\mathrm{CO}_{2}$, and some sub cooling, it splits into five streams, each expanded by a valve to a different pressure defined by the stage of the $\mathrm{CF}_{4}$ compressor to which it will return. This produces a stepping effect in the heat exchanger that overcomes entropy losses against contact liquid and other streams undergoing sensible heating/cooling.

$\mathrm{CO}_{2}$-Rich Product. The $\mathrm{CO}_{2}$ separates from the slurry at the bottom of the desublimation column in a hydrocyclone followed by a continuous press filter. After filtration, the $\mathrm{CO}_{2}$-rich product is $93.3 \% \mathrm{CO}_{2}$ and warms and melts against condensing $\mathrm{CF}_{4}$. After warming against the flue gas to $233 \mathrm{~K}$, the $\mathrm{CO}_{2}$-rich stream enters a contact liquid removal process for final separation ( $99.2 \% \mathrm{CO}_{2}$ purity). As part of the contact liquid removal, the $\mathrm{CO}_{2^{-}}$ rich stream warms and flashes to remove the remaining contact liquid. The $\mathrm{CO}_{2}$ vapor warms and recompresses before liquefying against the vaporizing $\mathrm{CO}_{2}$-rich stream. After liquefaction, a liquid pump pressurizes it to $100 \mathrm{bar}$ with cooling duty once again recovered before leaving the process for EOR or sequestration. Some studies suggest that a higher discharge pressure may be necessary ${ }^{69-71}$, which case is investigated in the sensitivity analysis.

External Cooling. Even with significant heat integration, the CCC-ECL process requires additional refrigeration. Natural gas acts as a refrigerant due to its reasonable 
pressure/temperature refrigeration capability, high maturity and availability of compression, and its potential to enable energy storage. It is nominally composed of $95 \% \mathrm{CH}_{4}, 3 \% \mathrm{C}_{2} \mathrm{H}_{6}$, and $2 \%$ $\mathrm{C}_{3} \mathrm{H}_{8}$. The natural gas liquefies and cools to $179 \mathrm{~K}$ before expanding in a turbine to $1,145 \mathrm{kPa}$ resulting in a temperature of $153 \mathrm{~K}$. The expansion vaporizes a significant fraction, $25.4 \%$, with the remaining natural gas vaporizing to cool contact liquid in the CCC-ECL process for subsequent $\mathrm{CO}_{2}$ desublimation. This expanded natural gas is the coldest temperature achieved in the CCC-ECL process. The natural gas recuperatively warms against incoming natural gas before being compressed to initial conditions. A mixed refrigerant loop supports the natural gas liquefaction and comprises nominally $4.2 \% \mathrm{CH}_{4}, 84.5 \% \mathrm{C}_{2} \mathrm{H}_{6}, 2.8 \% \mathrm{C}_{4} \mathrm{H}_{10}$, and $8.5 \%$ iso$\mathrm{C}_{5} \mathrm{H}_{12}$. Because of the heavier hydrocarbons in the mixed refrigerant, the compressor intercoolers must have a phase separator, and a pump removes and pressurizes the liquid. Alternatively, the recirculating natural gas stream could be conditioned such that no liquids condense to simplify the compressor operation.

Pressurization. The flue gas blower is a single-stage compressor in Aspen Plus. The $\mathrm{CF}_{4}$, natural gas, and mixed refrigerant compressors are 8-stage compressors with intercoolers after each stage of compression. The $\mathrm{CO}_{2}$ vapor compressor is a single-stage compressor with no after-cooler. Compressor intercoolers have a $5 \mathrm{kPa}$ pressure drop per pass, greatly affecting the efficiency of the lowest-pressure stages. Compressors operate with $90 \%$ polytropic efficiency, typical of commercial guarantees for such equipment at this scale. Compressor energy consumption is the primary energy demand in the CCC-ECL process, and thus under great scrutiny.

Heat Exchange. Brazed-plate heat exchangers are the primary heat exchange in the CCC-ECL system. They operate with a $1 \mathrm{~K}$ minimum internal temperature approach. The melting $\mathrm{CO}_{2}$ heat exchanger is similar in design to a jacketed, stirred tank with the $\mathrm{CF}_{4}$ condensing in the jacketing tubes while the solid melts and is stirred on the inside of the tank. A conservative approach simulates this as a co-current heat exchanger with $1 \mathrm{~K}$ approach temperature on the exiting streams. A full-scale counter-current implementation of the melting heat exchanger would have higher efficiency.

Other, more traditional heat exchangers provide compression inter-stage cooling and water cooling. Basic compressor inter-stage coolers are shell and tube heat exchangers with a minimum internal approach temperature of $5 \mathrm{~K}$, though brazed-plate systems would increase efficiency decrease cost. The evaporative cooler is a 10-stage cooling column. All heat exchangers have at least a $5 \mathrm{kPa}$ pressure drop per pass. Designs from Chart Energy and Chemicals suggest pressure drops ranging from $2 \mathrm{kPa}$ to $19 \mathrm{kPa}$ and these are included in the sensitivity analysis.

A 10-stage desublimation column uses a series of Gibbs reactors in the simulation, allowing solids formation at each stage. The desublimation column has $5 \mathrm{~cm}$ of liquid height per 
474 stage, resulting in a $0.37 \mathrm{kPa}$ pressure drop per stage. As an alternative to a desublimation 475 column, experimental results on a desublimation spray tower have improved efficiencies for heat 476 and mass transfer. Up to $96 \% \mathrm{CO}_{2}$ capture has been demonstrated and predictions of 477 performance are within $2.3 \%^{72}$. Pending future research and development, the desublimation 478 spray tower may provide opportunities for lowering the total energy penalty of the CCC-ECL 479 process.

480 Solid Separation. The $\mathrm{CO}_{2}$ solids separator is a combination of a hydrocyclone, to 481 concentrate the solid $\mathrm{CO}_{2}$ particles, followed by a continuous press filter, removing contact 482 liquid down to $6.7 \%$. The press filter captures $100 \%$ of the solid $\mathrm{CO}_{2}$. This does not take 483 solubility into account, which may increase the concentration of $\mathrm{CO}_{2}$ in the recycled contact 484 liquid, but this will simply recirculate and should not affect energy or cost. It may help reduce 485 viscosity.

486 Turbines. The two expansion turbines handle vapor-liquid phases. Turbines have $92 \%$ 487 isentropic efficiency. The turbines operate at temperatures ranging from 154-195 $\mathrm{K}$ and expand 488 the hydrocarbon liquids with a portion of the stream vaporizing. LNG operations employ 489 cryogenic hydraulic turbines that operate at nearly the same conditions and on the same scale ${ }^{73}$ 490 as those in this model. Valves could replace the turbines to reduce capital expenditures with only 491 a $2.4 \%$ increase in energy demand.

\section{RESULTS SUMMARY \& DISCUSSION}

CCC-ECL is capable of $90 \% \mathrm{CO}_{2}$ capture with a simulated energy penalty of 0.74 $494 \mathrm{MJ}_{\mathrm{e}} / \mathrm{kg} \mathrm{CO}$. Table 4 summarizes the energy consumption. Three compressors drive the 495 refrigeration and account for $80.9 \%$ of the total energy penalty. The majority of the remaining 496 energy penalty is due to the flue gas blower. The flue gas blower overcomes pressure drop and 497 accounts for $16.7 \%$ of the total energy penalty. The energy consumption of the blower may 498 decrease by creating lower discharge pressures. Lower discharge pressures occur with improved 499 cooling towers. The remaining power consumption is $2.4 \%$ of the total energy penalty and thus 500 less significant potential for improvement from an energy penalty perspective.

$501 \quad$ Table $3 \quad$ Energy requirement by unit

\begin{tabular}{lr}
\hline Unit & $\begin{array}{r}\text { Energy } \\
\text { Required }\end{array}$ \\
& {$\left[\mathrm{MW}_{\mathrm{e}}\right]$} \\
\hline Blower & 13.76 \\
$\mathrm{CF}_{4}$ Compressor & 27.93 \\
$\mathrm{CO}_{2}$ Compressor & 0.70 \\
Natural Gas Compressor & 18.55 \\
Mixed Refrigerant Compressor & 20.37 \\
Contact Liquid and Slurry Pumps & 2.21
\end{tabular}


Liquid $\mathrm{CO}_{2}$ Pump $\quad 0.98$

Mixed Refrigerant Liquid Pumps $\quad 0.11$

Natural Gas Turbine $\quad-1.38$

Mixed Refrigerant Turbine $\quad-0.63$

Total 82.59

503 Table 4 details the total energy balance, including the previously discussed $82.6 \mathrm{MW}_{\mathrm{e}}$ of 504 power consumed by process equipment. Process losses match the heat in/out of the plant and are 505 less than $0.27 \%$ of total heat as benchmarked by NETL ${ }^{74}$.

506 Table 4 Energy balance

\begin{tabular}{lrrr}
\hline & $\begin{array}{r}\text { Sensible } \\
\text { + Latent }\end{array}$ & Power & Total \\
\hline Heat In & {$[\mathbf{M W}]$} & {$[\mathbf{M W}]$} & {$[\mathbf{M W}]$} \\
\hline Flue Gas & -1860.4 & & -1860.4 \\
Makeup Contact Liquid & -3.8 & & -3.8 \\
Cooling Water & -13426.4 & & -13426.4 \\
Process Units & & 82.6 & 82.6 \\
Totals & $\mathbf{- 1 5 2 9 0 . 6}$ & $\mathbf{8 2 . 6}$ & $\mathbf{- 1 5 2 0 8 . 0}$ \\
\hline Heat Out & & & \\
\hline Cooling Water & -14252.9 & & -14252.9 \\
N $_{2}$-Rich Gas & -178.7 & & -178.7 \\
CO 2 -Rich Liquid & -1037.1 & & -1037.1 \\
Water Condensate 991 & 157.0 & & 157.0 \\
E416A & -28.2 & & -28.2 \\
E416B & 29.2 & & 29.2 \\
E416C & -0.9 & & -0.9 \\
C306 Cooling Water & 32.7 & & 32.7 \\
C570 Cooling Water & 21.4 & & 21.4 \\
C700 Cooling Water & 44.2 & & 44.2 \\
Process Losses* & 5.4 & & 5.4 \\
Totals & $\mathbf{1 5 2 0 8 . 0}$ & $\mathbf{0 . 0}$ & $\mathbf{- 1 5 2 0 8 . 0}$ \\
\hline Difference & & & $\mathbf{0 . 0}$ \\
\hline
\end{tabular}

508 Table 5 summarizes the mass balance based on the full-scale simulation. The total mass 509 balance closes within $0.01 \%$.

510 Table 5 Mass balance (flow rates in $\mathrm{kg} / \mathrm{hr}$ )

\begin{tabular}{lrrrrrrr}
\hline In & & & \multicolumn{3}{c}{ Contacting } \\
liquid & Ar & Total \\
\hline Flue Gas & 57726 & 1433810 & 447670 & 205464 & 0 & 24608 & 2169278
\end{tabular}




\begin{tabular}{lrrrrrrr} 
Makeup & & & & & & & \\
Contacting liquid & 0 & 0 & 0 & 0 & 5483 & 0 & 5483 \\
Water & 0 & 28 & 44 & 3020154 & 0 & 0 & 3020226 \\
Totals & $\mathbf{5 7 7 2 6}$ & $\mathbf{1 4 3 3 8 3 8}$ & $\mathbf{4 4 7 7 1 4}$ & $\mathbf{3 2 2 5 6 1 8}$ & $\mathbf{5 4 8 3}$ & $\mathbf{2 4 6 0 8}$ & $\mathbf{5 1 9 4 9 8 7}$ \\
\hline & & & & & Contacting & & \\
Out & $\mathbf{O}_{\mathbf{2}}$ & $\mathbf{N}_{\mathbf{2}}$ & $\mathbf{C O}_{\mathbf{2}}$ & $\mathbf{H}_{\mathbf{2}} \mathbf{O}$ & liquid & Ar & Total \\
\hline $\mathrm{N}_{2}$-Rich Gas & 57726 & 1433782 & 43834 & 17439 & 72 & 24608 & 1577461 \\
$\mathrm{CO}_{2}$-Rich Liquid & 0 & 0 & 403836 & 0 & 5339 & 0 & 409175 \\
Water & 0 & 56 & 88 & 3208179 & 0 & 0 & 3208323 \\
Totals & $\mathbf{5 7 7 2 6}$ & $\mathbf{1 4 3 3 8 3 8}$ & $\mathbf{4 4 7 7 5 8}$ & $\mathbf{3 2 2 5 6 1 8}$ & $\mathbf{5 4 1 1}$ & $\mathbf{2 4 6 0 8}$ & $\mathbf{5 1 9 4 9 5 9}$ \\
\hline Rel. Difference & $\mathbf{0 . 0 0 0}$ & $\mathbf{0 . 0 0 0}$ & $\mathbf{0 . 0 0 0}$ & $\mathbf{0 . 0 0 0}$ & $\mathbf{0 . 0 0 3}$ & $\mathbf{0 . 0 0 0}$ & $\mathbf{0 . 0 0 0}$ \\
\hline
\end{tabular}

Some contacting liquid in the system is lost during direct contact with the flue gas and during $\mathrm{CO}_{2}$ separation in a flash drum. The concerns are primarily the environmental and economic impact of the combined losses. As simulated, the contacting liquid present in the exhausted $\mathrm{N}_{2}$-rich gas is acceptable by EPA source guidelines for hydrocarbon emissions. Contacting liquid in the $\mathrm{CO}_{2}$-rich stream is of lesser environmental concern since similar hydrocarbons exists in the ground where the $\mathrm{CO}_{2}$ will be used for EOR. The economic impact of the contacting liquid losses at full-scale implementation of CCC-ECL will likely change the economics of its supply and demand. However, hydrocarbons suitable as contacting liquid generally come from oil and gas fractionation, with potential supplies greatly outweighing any potential need. Experimental tests completed with many hydrocarbons generally indicate that losses will be minor.

A sensitivity analysis shows the effects of variations from the current base model. These variation reflect an industry review of common challenges, available technologies, and expected technological improvements. Table 6 shows the results of the sensitivity analysis. The $4 \% \mathrm{CO}_{2}$ inlet variation corresponds to a natural gas combined cycle power plant that has less $\mathrm{CO}_{2}$ emissions per unit power produced. Excluding the natural gas case, the energy penalty ranges from $0.71-0.92 \mathrm{MJ}_{\mathrm{e}} / \mathrm{kg} \mathrm{CO}_{2}$, which compares very favorably with other technologies.

If high-pressure is required for EOR or sequestration as suggested by some studies ${ }^{69,71}$, the energy penalty would increase by $0.004 \mathrm{MJ}_{\mathrm{e}} / \mathrm{kg} \mathrm{CO}_{2}$. Without the turbines on the liquid natural gas and mixed refrigerant streams, the process loses $2.1 \mathrm{MW}_{\mathrm{e}}$ and the energy penalty would increase by $0.016 \mathrm{MJ}_{\mathrm{e}} / \mathrm{kg} \mathrm{CO}_{2}$.

An economic analysis used the same scenarios as the energy sensitivity analysis. All 534 equipment prices came from Aspen Plus' built-in economic analysis, excluding multi-stream 535 heat exchangers. A price quote from Chart Energy and Chemicals provided the basis for the 536 multi-stream heat exchangers in the model. Deviations from the base scenario have a price 537 difference equal to $86 \$ / \mathrm{m}^{2}$ multiplied by the change in heat transfer area. The change in heat 538 transfer area assumed that $\mathrm{U}$ and $\Delta \mathrm{T}$ were constant in the equation 
540 where $U$ is the heat transfer coefficient, $A$ is the heat transfer area, $\Delta T$ is a correlation for the 541 temperature difference inside a plate and frame heat exchanger, and $Q$ is the heat duty. $U \Delta T$ is 542 the quotient of the heat duty calculated by Aspen Plus for the base case and the area for the heat 543 exchanger as determined by Chart. This value determined the new area with heat duties 544 calculated by Aspen Plus for each scenario. Table 6 shows the capital expenditure (CAPEX) 545 attributed to carbon capture, energy penalty, and cost of electricity (COE). The $4 \% \mathrm{CO}_{2}$ inlet 546 case refers to a natural gas power plant and is the cheapest scenario in the analysis.

547 Table 6 Economic analysis of process variations and resulting cost of electricity (COE)

\begin{tabular}{|c|c|c|c|c|c|}
\hline Case / Variable & Base Case & Variation & $\begin{array}{l}\text { CAPEX } \\
{\left[\$ \times 10^{6}\right]}\end{array}$ & $\begin{array}{c}\text { Energy Penalty } \\
{\left[\mathrm{MJ}_{\mathrm{e}} / \mathrm{kg} \mathrm{CO}_{2}\right]}\end{array}$ & $\begin{array}{c}\mathrm{COE} \\
{[\text { cents/kWh] }}\end{array}$ \\
\hline No $\mathrm{CO}_{2}$ Capture & & & - & - & 5.89 \\
\hline Amine $\mathrm{CO}_{2}$ Capture & & & 469 & 1.379 & 10.65 \\
\hline Base CCC-ECL Case & & & 361 & 0.738 & 8.96 \\
\hline \multirow{3}{*}{$\mathrm{CO}_{2}$ Inlet } & \multirow{3}{*}{$16 \%$} & $4 \%$ & 217 & 1.669 & 6.67 \\
\hline & & $12 \%$ & 345 & 0.920 & 8.74 \\
\hline & & $14 \%$ & 357 & 0.819 & 8.89 \\
\hline \multirow{3}{*}{$\mathrm{CO}_{2}$ Capture } & \multirow{3}{*}{$90 \%$} & $89 \%$ & 359 & 0.711 & 8.93 \\
\hline & & $91 \%$ & 365 & 0.740 & 9.03 \\
\hline & & $99 \%$ & 391 & 0.846 & 9.45 \\
\hline \multirow{2}{*}{ Cooling Water Temp } & \multirow{2}{*}{$289 \mathrm{~K}$} & $281 \mathrm{~K}$ & 362 & 0.717 & 8.97 \\
\hline & & $303 \mathrm{~K}$ & 367 & 0.772 & 9.06 \\
\hline \multirow{2}{*}{ Efficient Turbines ${ }^{\mathrm{A}}$} & \multirow{2}{*}{$92 \%$} & $89 \%$ & 364 & 0.738 & 9.00 \\
\hline & & $94 \%$ & 366 & 0.737 & 9.07 \\
\hline \multirow{2}{*}{ HX Temp Approach } & \multirow{2}{*}{$1 \mathrm{~K}$} & $2 \mathrm{~K}$ & 318 & 0.772 & 8.88 \\
\hline & & $4 \mathrm{~K}$ & 299 & 0.863 & 8.95 \\
\hline Pressure Drop & $5 \mathrm{kPa}$ & Mfg Quote & 369 & 0.832 & 9.16 \\
\hline \multirow{6}{*}{ Compressor Efficiency $^{\mathrm{B}}$} & \multirow{6}{*}{$90 \%$} & $85 \% \mathrm{CF}_{4}$ & 363 & 0.752 & 9.02 \\
\hline & & $92 \% \mathrm{CF}_{4}$ & 362 & 0.732 & 8.99 \\
\hline & & $85 \% \mathrm{NG}$ & 363 & 0.747 & 9.01 \\
\hline & & $92 \% \mathrm{NG}$ & 362 & 0.734 & 8.99 \\
\hline & & $85 \% \mathrm{MR}$ & 363 & 0.748 & 9.01 \\
\hline & & $92 \% \mathrm{MR}$ & 362 & 0.733 & 8.99 \\
\hline \multirow{2}{*}{ Blower Efficiency $^{\mathrm{B}}$} & \multirow{2}{*}{$90 \%$} & $85 \%$ & 363 & 0.745 & 9.01 \\
\hline & & $92 \%$ & 362 & 0.734 & 8.99 \\
\hline
\end{tabular}


550 CONCLUSIONS

551 CCC-ECL experiments at several scales up to 1 tonne per day demonstrate the process 552 feasibility and robustness. These experiments also provide data with which to compare CCC553 ECL simulations over a broad range of operating conditions and in both steady and transient 554 modes. CCC-ECL simulations reliably track observed behaviors in all but the most extreme 555 startup and shutdown scenarios and in all reasonably steady scenarios. Equilibrium predictions of 556 solid $\mathrm{CO}_{2}$ formation agree with both lab- and skid-scale data. Basic operation on small-scale 557 systems demonstrate $90 \% \mathrm{CO}_{2}$ capture on flue gas streams as high as $1.4 \mathrm{~m}^{3} / \mathrm{min}$. The $\mathrm{CO}_{2}$ 558 stream produced by the CCC-ECL process has a relatively high purity of $99.2 \% \mathrm{CO}_{2}$. The 559 emissions of volatile hydrocarbons from CCC-ECL meets current EPA source emission 560 guidelines and total contact liquid losses should not be economically constraining.

CCC-ECL simulations for retrofit of a $550 \mathrm{MW}_{\mathrm{e}}$ coal-fired power plant indicate an 562 energy penalty for $90 \% \mathrm{CO}_{2}$ capture of $0.74 \mathrm{MJ}_{\mathrm{e}} / \mathrm{kg} \mathrm{CO}_{2}$ captured. Reasonable best- and worst563 case scenarios are between $0.71-0.92 \mathrm{MJ}_{\mathrm{e}} / \mathrm{kg} \mathrm{CO}_{2}$ captured. The estimated energy penalty is 1.67 $564 \mathrm{MJ}_{\mathrm{e}} / \mathrm{kg} \mathrm{CO}$ in the case of CCC-ECL implementation for a natural gas combined cycle power 565 plant (4\% $\mathrm{CO}_{2}$ inlet concentration). The estimated cost of the CCC-ECL retrofit for this plant is $566 \$ 361$ MM Capex. The financial result is an increased cost of electricity in the range of 2.85-3.56 567 cents/kWh. The energy and cost numbers compare favorably with alternative systems. 


\section{Author Contributions}

The manuscript was written through contributions of all authors. All authors have given approval to the final version of the manuscript.

\section{Acknowledgments}

575 The information, data, or work presented herein was funded by Sustainable Energy Solutions

576 LLC of Orem, Utah, the Advanced Research Projects Agency - Energy (ARPA-E), U.S. 577 Department of

578 Energy, under Award Number DE-AR0000101, the Climate Change and Emissions Management 579 Corporation (CCEMC) of Alberta, Canada, and the Advanced Conversion Technologies Task 580 Force in Laramie, Wyoming. Sustainable Energy Solutions is the owner of the Cryogenic Carbon 581 Capture (CCC) technology portfolio.

\section{Disclaimer}

584 The information, data, or work presented herein was funded in part by an agency of the United 585 States Government. Neither the United States Government nor any agency thereof, nor any of 586 their employees, makes any warranty, express or implied, or assumes any legal liability or 587 responsibility for the accuracy, completeness, or usefulness of any information, apparatus, 588 product, or process disclosed, or represents that its use would not infringe privately owned rights. 589 Reference herein to any specific commercial product, process, or service by trade name, 590 trademark, manufacturer, or otherwise does not necessarily constitute or imply its endorsement, 591 recommendation, or favoring by the United States Government or any agency thereof. The views 592 and opinions of authors expressed herein do not necessarily state or reflect those of the United 593 States Government or any agency thereof.

\section{REFERENCES}

596 1. Environmental Protection Agency, 2014, pp. 34829 -34958.

597 2. J. Kislear, presented in part at the Research Experience in Carbon Sequestration, $598 \quad$ Birmingham, AL, 2014.

599 3. D. Berstad, R. Anantharaman and P. Nekså, International Journal of Refrigeration, 2013, 600 36, 1403-1416.

601 4. J. Davison and K. Thambimuthu, Proceedings of the Institution of Mechanical Engineers, 602 Part A: Journal of Power and Energy, 2009, 223, 201-212.

603 5. T. E. Rufford, S. Smart, G. C. Y. Watson, B. F. Graham, J. Boxall, J. C. D. da Costa and E. F. May, J. Pet. Sci. Eng., 2012, 94-95, 123-154.

6. J. Wilcox, R. Haghpanah, E. C. Rupp, J. He and K. Lee, Annual Review of Chemical and Biomolecular Engineering, 2014, 5, 479-505.

7. M. Matuszewski, J. Ciferno, J. J. Marano and S. S. Chen, Research and Development Goals for CO2 Capture Technology, NETL, 2011. 
8. K. Gerdes, M. Matuszewski and V. Chou, NETL, DOE, 2014.

6109 9. E. T. L. US Department of Energy, Cost and Performance Baseline for Fossil Energy

$611 \quad$ Plants Volume 1: Bituminous Coal and Natural Gas to Electricity 2013.

612 10. National Energy Technology Laboratory, ed. Department of Energy, 2013, vol. 1.

613 11. N. E. T. L. US Department of Energy, Cost and Performance of PC and IGCC Plants for

614

12. K. Gerdes, presented in part at the $2014 \mathrm{NETL} \mathrm{CO}_{2}$ Capture Technology Meeting, Pittsburgh, PA, July 29, 2014, 2014.

13. D. E. Herzog H, Tester J, Rosenthal R., A research needs assessment for the capture, utilization and disposal of carbon dioxide from fossil fuel-fired power plans. , Massachusetts Institute of Technology, Energy Laboratory, 1993.

14. J. Ciferno, Pulverized Coal Oxycombustion Power Plants, NETL, 2008.

15. A. Gopan, B. M. Kumfer, J. Phillips, D. Thimsen, R. Smith and R. L. Axelbaum, Applied Energy, 2014, 125, 179-188.

16. N. Berguerand and A. Lyngfelt, Fuel, 2008, 87, 2713-2726.

17. P. Cho, T. Mattisson and A. Lyngfelt, Fuel, 2004, 83, 1215-1225.

18. L.-S. Fan, L. Zeng, W. Wang and S. Luo, Energy Environ. Sci., 2012, 5, 7254-7280.

19. L.-S. Fan, presented in part at the NETL CO2 Capture Technology Meeting, Pittsburgh, PA, 2012.

20. A. Tong, S. Bayham, M. V. Kathe, L. Zeng, S. Luo and L.-S. Fan, Applied Energy, 2014, 113, 1836-1845.

21. National Energy Technology Laboratory, Advanced Carbon Dioxide Capture R\&D Program: Technology Update, U. D. o. Energy, 2013.

22. M. H. L. Zaman, Jay, Korean Journal of Chemical Engineering, 2013, 30, 1497-1526.

23. A. Skorek-Osikowska, K. Janusz-Szymańska and J. Kotowicz, Energy, 2012, 45, 92-100.

24. E. Sanchez Fernandez, E. L. V. Goetheer, G. Manzolini, E. Macchi, S. Rezvani and T. J. H. Vlugt, Fuel, 2014, 129, 318-329.

25. F. Porcheron, A. Gibert, M. Jacquin, P. Mougin, A. Faraj, A. Goulon, P.-A. Bouillon, B. Delfort, D. Le Pennec and L. Raynal, Energy Procedia, 2011, 4, 15-22.

26. F. Morton, R. Laird and J. Northington, Energy Procedia, 2013, 37, 525-539.

27. Y. Le Moullec and M. Kanniche, International Journal of Greenhouse Gas Control, 2011, 5, 727-740.

28. L. Duan, M. Zhao and Y. Yang, Energy, 2012, 45, 107-116.

29. S. M. Cohen, G. T. Rochelle and M. E. Webber, International Journal of Greenhouse Gas Control, 2012, 8, 180-195.

30. Z. Amrollahi, P. A. M. Ystad, I. S. Ertesvåg and O. Bolland, International Journal of Greenhouse Gas Control, 2012, 8, 1-11.

31. M. E. Boot-Handford, J. C. Abanades, E. J. Anthony, M. J. Blunt, S. Brandani, N. Mac Dowell, J. R. Fernandez, M.-C. Ferrari, R. Gross, J. P. Hallett, R. S. Haszeldine, P. Heptonstall, A. Lyngfelt, Z. Makuch, E. Mangano, R. T. J. Porter, M. Pourkashanian, G. T. Rochelle, N. Shah, J. G. Yao and P. S. Fennell, Energy Environ. Sci., 2014, 7, 130189.

32. M. Ishibashi, H. Ota, N. Akutsu, S. Umeda, M. Tajika, J. Izumi, A. Yasutake, T. Kabata and Y. Kageyama, Energy Conversion and Management, 1996, 37, 929-933.

33. E. Chabanon, D. Roizard and E. Favre, Chemical Engineering Science, 2013, 87, 393407. 
34. M. Gazzani, D. M. Turi, A. F. Ghoniem, E. Macchi and G. Manzolini, International Journal of Greenhouse Gas Control, 2014, 25, 62-78.

35. M. Sjardin, K. Damen and A. Faaij, Energy, 2006, 31, 2523-2555.

36. P. Shao, M. M. Dal-Cin, M. D. Guiver and A. Kumar, Journal of Membrane Science, 2013, 427, 451-459.

37. C. A. Scholes, M. T. Ho, A. A. Aguiar, D. E. Wiley, G. W. Stevens and S. E. Kentish, International Journal of Greenhouse Gas Control, 2014, 24, 78-86.

38. D. Clodic, R. El Hitti, M. Younes, A. Bill and F. Casier, Alexandria, Virginia, 2005.

39. X. Pan, D. Clodic and J. Toubassy, Greenhouse Gases: Science and Technology, 2013, 3, 8-20.

40. M. J. Tuinier, M. van Sint Annaland, G. J. Kramer and J. A. M. Kuipers, Chemical Engineering Science, 2010, 65, 114-119.

41. A. Castrogiovanni, V. Balepin, A. Robertson and B. Calayag, Pittsburgh, PA, 2012.

42. R. Span and W. Wagner, Journal of Physical and Chemical Reference Data, 1996, 25, 1509-1596.

43. C. E. Bryson, V. Cazcarra and L. L. J. Levenson, Chemical Engineering Data, 1974, 19.

44. A. W. Tickner and F. P. Lossing, Phys. Colloid Chem., 1951, 733-740.

45. D. R. Stull, Industrial \& Engineering Chemistry, 1947, 517-540.

46. G. W. C. Kaye and T. H. Laby, Tables of Physical and Chemical Constants, 14th ed., Longman Group Limited, London, 1973.

47. Thermodynamics Research Center, Texas A\&M University, College Station, TX.

48. W. F. Giauque and C. J. Egan, J. Chem. Phys., 1937, 5.

49. Z. Bilkadi, M. W. Lee and J. Bigeleisen, The Journal of Chemical Physics, 1975, 62, 2087-2093.

50. D. Ambrose, Transactions of the Faraday Society, 1956, 52, 772-781.

51. W. Heuse and J. Otto, Annalen der Physik, 1931, 401, 486-504.

52. E. Fernandez-Fassnacht and F. Del Rio, J. Chem. Thermodyn., 1984, 16.

53. C. H. Meyers and M. S. Van Dusen, Journal of Research of the National Bureau of Standards, 1933, 10, 381-412.

54. J. C. Mullins, B. S. Kirk and W. T. Ziegler, Calculation of the Vapor Pressure and Heats of Vaporization and Sublimation of Liquids and Solids, Especially below One Atmosphere. V. Carbon Monoxide and Carbon Dioxide, Ga. Inst. Technol., 1963.

55. K. N. Marsh, Recommended Reference Materials for the Realization of Physicochemical Properties, Blackwell Sci. Pub., Oxford, 1987.

56. G. L. Baughman, S. P. Westhoff, S. Dincer, D. D. Duston and A. J. Kidnay, J. Chem. Thermodyn., 1974, 6.

57. DIPPR, Provo, UT, 2012.

58. NIST, 2012.

59. H. G. Donnelly and D. L. Katz, Industrial \& Engineering Chemistry, 1954, 46, 511-517.

60. S. I. Sandler, Chemical, Biochemical, and Engineering Thermodynamics, John Wiley \& Sons, Inc., 4th edn., 2006.

61. G. M. Agrawal and R. J. Laverman, Adv. Cryog. Eng., 1974, 19, 327-338.

62. M. J. Pikaar, Imperial College of Science and Technology, 1959.

63. L. Zhang, R. Burgass, A. Chapoy, B. Tohidi and E. Solbraa, Journal of Chemical \& Engineering Data, 2011, 56, 2971-2975. 
64. Gas Proccesors Suppliers Association, GPSA Engineering Data Book, Tulsa, OK,

65. T. T. Le and M. A. Trebble, Journal of Chemical \& Engineering Data, 2007, 52, 683686.

66. F. Kurata, GPA, 1974.

67. US8764885, 2014.

68. US8715401, 2014.

69. E. A. Chukwudeme and A. A. Hamouda, Energies, 2009, 2, 714-737.

70. G. Chen, X. Wang, Z. Liang, R. Gao, T. Sema, P. Luo, F. Zeng and P. Tontiwachwuthikul, Energy Procedia, 2013, 37, 6877-6884.

71. K. Su, X. Liao, X. Zhao and H. Zhang, Energy \& Fuels, 2013, 27, 378-386.

72. B. J. Nielson, Master of Science, Brigham Young University, 2013.

73. L. L. Johnson and G. Renaudin, Journal Name: Oil and Gas Journal; Journal Volume: 94; Journal Issue: 47; Other Information: PBD: 18 Nov 1996, 1996, Medium: X; Size: pp. 31-36.

74. N. E. T. L. US Department of Energy, Pulverized Coal Oxycombustion Power Plants Volume 1: Bituminous Coal to Electricity: Revision 2, 2008. 